\title{
Caracterización y problemática del presidencialismo iberoamericano
}

María de la Paz Sánchez Manzano

\section{Introducción}

Característica común de los sistemas políticos contemporáneos, parlamentarios o presidenciales, es el predominio del Poder Ejecutivo sobre los otros poderes. Los órganos legislativos se nos revelan «incapaces de asumir las funciones que exige la democracia económica debido, principalmente, a la lentitud del procedimiento legislativo [...] $)^{1}$. Es decir, "la creciente importancia y complejidad que caracterizan al conjunto de actividades desarrolladas por el Poder Ejecutivo, se han convertido en uno de los rasgos que mejor tipifica el funcionamiento de los Estados modernos. De este modo, nos es fácil observar que los poderes ejecutivos actuales, representan el tipo de estructura gubernamental que

1 Domingo Alfonso Bacalao Octavio, «El fortalecimiento del Ejecutivo y la delegación legislativa", Anuario, Instituto de Derecho Comparado, Valencia, Venezuela, $N^{\circ} 10,1978$, p. 87. En semejantes términos, Antonio Carro Martínez, "La Primacía del Poder Ejecutivo en el Estado Contemporáneo", Revista de Estudios Políticos, N $^{\circ}$ 98, p. 124 y ss. Según este autor a lo largo de las últimas décadas el Ejecutivo se ha robustecido a través de tres tipos de funciones: la función militar, la función diplomática y, por último, la función de planificación. Por su parte, Carpizo afina un poco más y hace la siguiente relación de factores que han influido en casi todos los países en el fenómeno contemporáneo de un poder Ejecutivo fuerte: los problemas económicos, sociales y de planeación; los problemas de defensa y militares; su papel en las relaciones internacionales; la delegación de facultades legislativas y el control de la opinión pública a través de los medios masivos de información. Véase, Jorge Carpizo, El Presidencialismo mexicano, México, Siglo XXI Editorial, 1978 (1² edición), pp. $19-23$. 
más rápidamente parece haberse adaptado a las nuevas exigencias funcionales que caracterizan a los sistemas políticos actuales [...]. En otras palabras, los rasgos organizativos que caracterizan al Poder Ejecutivo parecen ser la razón por la cual sea éste, y no el Parlamento, la estructura gubernamental sobre la que se ha ido acumulando una proporción mayor de las funciones públicas»?. .

Las principales características del fenómeno que acabamos de apuntar se dan en América Latina, donde puede hablarse de la existencia de poderes ejecutivos "fuertes o dominantes» ${ }^{3}$. Si bien en América Latina se mantiene el principio de separación de poderes en sus rasgos fundamentales ${ }^{4}$, inmediatamente ha de puntualizarse que se introducen algunas variaciones respecto al modelo norteamericano, que imposibilitan el juego de los checks and balances y que tienden a reforzar al Ejecutivo en menoscabo del Poder Legislativo, dadas las exigencias requeridas por la condición de países en vías de desarrollo de los países latinoamericanos ${ }^{5}$. Jacques Lambert introduce una nueva terminología

2 Waldino Suárez, «El Poder Ejecutivo en América Latina: su capacidad operativa bajo regímenes presidencialistas de Gobierno", Revista de Estudios Políticos, N $^{\circ} 29$, 1982, pp. 109-110.

3 Ibidem, p. 110. Ahora bien, se constata que en la historia política latinoamericana ha venido librándose una lucha histórica fundamental entre dos tesis opuestas, el Ejecutivo fuerte (caracterizado por un mandato presidencial prolongado, una amplia esfera de atribuciones y escasas obligaciones, extensa potestad de nombramiento, facultades extraordinarias vagas e imprecisas y sujeción del Legislativo y del Judicial) y el Ejecutivo débil, que se pone en vigor durante los cortos intervalos de anarquía o democratización (y que presenta los rasgos opuestos a los anteriores: breve mandato presidencial, precisa descripción de las facultades, cláusula de no-reelección, incorporación de algunos matices parlamentarios y aumento del control político por parte del Legislativo y del Judicial hacia el Ejecutivo). Frente a ello Valencia Carmona propone «superar la querella tradicional entre Ejecutivo fuerte y Ejecutivo débil, mediante una fórmula que recoja lo mejor de ambas tesis. Se demanda un ejecutivo enérgico, dotado de una amplia esfera de acción, que pueda realizar reformas sociales en un universo problemático, pero al propio tiempo que tenga límites a su actividad, que los controles operen y lo ciñan siempre a la vía de la legalidad". Salvador Valencia Carmona, El Poder Ejecutivo Latinoamericano, México, UNAM, 1979, pp. 94 - 96.

4 Discrepa de esta opinión, ampliamente extendida, Carpizo, quien afirma que en América Latina no existe una verdadera separación de poderes, Jorge Carpizo, El Presidencialismo mexicano, op. cit., p. 17.

5 Viviana Krsticevic sostiene que los objetivos que se persiguen con la instaura- 
para poner de manifiesto estas variaciones y habla de la existencia de un "régimen de preponderancia presidencial», si bien en la actualidad se simplifica aún más y se habla, sencillamente, de presidencialismo, donde el sufijo -ismo alude a una exageración o hipertrofia del modelo o forma presidencial ${ }^{6}$. Es más, las peculiares condiciones sociales de los países latinoamericanos incluso van a permitir la configuración de variantes dentro del propio presidencialismo.

No puede olvidarse que han existido ejemplos parlamentarios en algunos países iberoamericanos ${ }^{7}$. En cualquier caso, pueden encontrar-

ción de la separación de poderes rígida promovida por el sistema presidencialista, apuntan hacia la consecución de: «[...] el logro de un sistema que evite los abusos de poder y preserve la seguridad, [...] la división para alcanzar resultados más eficientemente o bien generar mecanismos que permitan una efectiva toma de decisiones [...] y que los ciudadanos alcancen el máximo grado de autonomía posible». Véase en Viviana Krsticevic, "Presidencialismo en América Latina", en Nino y otros, El presidencialismo puesto a prueba, Centro de Estudios Constitucionales, Madrid, 1992, pp. 127 - 155 (la cita transcrita corresponde a la página 132). También, Jacques Lambert, América Latina. Estructuras sociales e instituciones políticas, Editorial Ariel, Barcelona-Caracas-México, 1978 (3a edición, reimpresión), pp. 57-58; Jacques Lambert, "La transposition du régime presidential hors des Etats Unis: le cas dell'Amérique Latine", Revue Française de Science Politique, Septiembre 1963, p. 581; Humberto Nogueira Alcalá "I Regimi Presidenziali de l'America Latina", Quaderni Costituzionali, a. VIII, número 3, Diciembre 1988, pp. 492-493; y Mario D. Serrafero, "Presidencialismo y reforma política en América Latina", Revista del Centro de Estudios Constitucionales, número 8, 1991, pp. 206-210.

6 Jacques Lambert, América Latina. (Estructuras sociales e instituciones políticas), op. cit., pp. 518 - 553 y Domingo García Belaunde, "Forma de Gobierno en la Constitución peruana", Revista de Estudios Políticos, No 74, 1991, p. 621. También Nogueira en el mismo sentido señala que el "presidencialismo latinoamericano ha sido denominado cesarismo representativo por ciertos autores, para quienes el régimen, si funciona correctamente, se diferencia de la dictadura por el hecho de que el poder del Jefe del Estado no es ilimitado ni arbitrario, que existe según una regla institucional preestablecida que respeta las otras instituciones y garantiza las libertades públicas, que su autoridad proviene de una elección popular competitiva y es limitada en el tiempo, el cual posee amplios poderes de los cuales sólo responde ante el pueblo que lo eligió, aún cuando comparte con un Parlamento con prerrogativas limitadas, ya que el Ejecutivo se convierte en colegislador". Humberto Nogueira Alcalá, "El Presidencialismo en la práctica política», Revista Síntesis, N³, Madrid, 1987, p. 13.

7 «Los ensayos de régimen parlamentario o han sido efímeros (Cuba, Brasil) o incompletos (Venezuela, Chile, Guatemala) o han derivado hacia formas peculiares (Uruguay)». Luis Sánchez Agesta, Curso de Derecho Constitucional Comparado, 
se preceptos constitucionales que, dentro de la fórmula presidencialista, reconocen facultades parlamentarias como la interpelación a los ministros y la posibilidad de voto de censura contra los mismos. Un fenómeno aislado lo constituye la experiencia del Ejecutivo colegiado en Uruguay, inspirado en el modelo suizo, que tuvo gran éxito mientras prosperó la economía del país ${ }^{8}$.

El trabajo que aquí comienza se propone, a partir del análisis de la normativa constitucional iberoamericana, apuntar las características y problemas anejos más sobresalientes del sistema presidencialista de esta región, si bien ha de tenerse en cuenta la dificultad que implica tratar de realizar un estudio de conjunto para toda ella, ya que, a pesar de contar con numerosos rasgos en común, posee, igualmente, diferencias que hacen imposible tratar de integrar a todos los países latinoamericanos en una misma categoría de situaciones absolutamente idénticas. No es tarea fácil elegir y sistematizar las muchas variables (casos particulares y variadas experiencias y circunstancias locales) que entran en juego para elaborar un estudio sobre el Poder Ejecutivo en América Latina?

Una precisión nos queda por hacer antes de comenzar, y es que aun cuando hablamos de un presidencialismo latinoamericano, hemos de reiterar que esta generalización no es exacta, pues el mismo no es reducible a un único tipo, sino que pueden distinguirse diversos tipos de presidencialismo en los distintos países de la región e incluso dentro de

Madrid, Universidad de Madrid, Facultad de Derecho, Sección de Publicaciones, 1976 ( $6^{a}$ edición), p. 240. También Viviana Krsticevic, quien además de apuntar a esos ensayos parlamentarios, señala que "también se intentaron desarrollos autóctonos como la curiosa Constitución de Bolivia de 1826", "Presidencialismo en América Latina», op. cit., p. 132. Una relación de los ensayos parlamentarios en la región latinoamericana puede encontrarse en Salvador Valencia Carmona, "Las tendencias contemporáneas del Ejecutivo Latinoamericano", op. cit., pp. 147-151.

8 En relación con Ejecutivo colegiado uruguayo consúltese, Carlos Ollero, «Uruguay. La Reforma Constitucional de 16 de Diciembre de 1951: el Ejecutivo colegiado», Revista de Estudios Políticos, N 62, 1952, pp. 139 - 155 y Salvador Valencia Carmona, «Las tendencias contemporáneas del Ejecutivo Latinoamericano», Boletín Mexicano de Derecho Comparado, No 31-32, 1978, pp. 150 - 153.

9 Ya Valencia Carmona en su obra, dedicada al estudio del Poder Ejecutivo en Latinoamérica resaltaba esta dificultad: «El Ejecutivo es una institución central no sólo en el orden jurídico, sino también en el orden político y social de nuestras naciones, de ahí que sea difícil explorar todos los matices e implicaciones tan diversas que ofrece». Salvador Valencia Carmona, op. cit., p. 13. 
la historia política de un mismo país ${ }^{10}$. Debido a su singular naturaleza, el presidencialismo latinoamericano ha provocado interpretaciones encontradas, hasta el punto de que se aprecia una cierta afición de los especialistas a elaborar tipologías en las que ubicar a las distintas repúblicas de la zona ${ }^{11}$.

Nosotros pensamos que en la actualidad los regímenes presidencialistas latinoamericanos pueden reconducirse a tres grandes categorías a saber: el presidencialismo autoritario (el régimen presidencial chileno), el presidencialismo puro (México) y el presidencialismo atenuado o parlamentario (Costa Rica). Aún así, independientemente de las tipologías ensayadas, podría intentarse una enumeración de los rasgos definitorios del sistema presidencial latinoamericano establecidos sobre la base de las facultades que tiene atribuidas el Ejecutivo. Sin embargo, a partir del estudio exhaustivo de los diferentes textos constitucionales, constatamos que enumeraciones de este tipo, pese a ser bastante ilustrativas, no resisten la prueba de la generalización a todos los regímenes presidenciales de la región, sino que existen casos de desviación respecto a aquellas características. Sobre la base de nuestro estudio, podemos adelantar que los rasgos comunes que definen a todos los presidencialismos latinoamericanos se resumen en los siguientes:

- la designación popular del Presidente y su legitimidad paralela a la del Parlamento.

- las amplias facultades del cargo (poderes de emergencia y facultades colegisladoras), si bien la extensión de las atribuciones competenciales varía según los casos, pero, en todo caso, son más amplias que en el

10 Así, por ejemplo, en el caso de Chile se han llegado a diferenciar cuatro formas de ejercicio presidencial: el Presidente gobernante (1833-1861); el Presidente condicionado (1861-1891); el Presidente neutral (1891-1925) y el Presidente negociador (1933-1973). Mario D. Serrafero, «Presidencialismo y reforma política en América Latina", op. cit., pp. 202-203.

11 Véase, a título de ejemplo, Humberto Nogueira Alcalá, "I Regimi Presidenziali dell'America Latina", op. cit., Pp. 507-518; Karl Lowenstein, Teoría de la Constitución, Ediciones Ariel, Barcelona, 1964, pp. 50-51, del mismo autor, "La presidencia fuera de los Estados Unidos», Boletín del Instituto de Derecho Comparado, México, $N^{\circ}$ 5, Mayo-septiembre, 1949, p. 15 y ss.; Luis Sánchez Agesta, Curso de Derecho Constitucional Comparado, op. cit., pp. 243-244 y Salvador Valencia Carmona, "Las tendencias contemporáneas del Ejecutivo en Latinoamérica», op. cit., pp. 142-147. 
modelo norteamericano, lo que desemboca, obviamente, en el predominio del Poder Ejecutivo frente al Legislativo

- la conflictiva relación con el Poder Legislativo

En los siguientes epígrafes pasamos a estudiar el conjunto de poderes ampliados que ostentan los Presidentes latinoamericanos y las limitaciones a las que se ven sometidos, pero antes de abordar este estudio es conveniente que detengamos nuestra atención en la cuestión de la elección presidencial. Al hilo de dicha caracterización, iremos analizando los posibles problemas que la misma plantea.

\section{La elección presidencial}

En el régimen presidencial, el Ejecutivo y el Legislativo poseen fuentes de legitimidad diversas, de manera que coexisten dos procesos electorales. Algunos autores ponen de manifiesto que aunque el presidencialismo pueda parecer, a primera vista, más democrático que el régimen parlamentario, en la medida en que los candidatos a jefatura del Estado/gobierno son elegidos por sufragio universal, no por coaliciones parlamentarias, dicha impresión puede ser engañosa, pues el régimen presidencialista facilita el nombramiento como presidentes a candidatos con poca experiencia político-administrativa (los denominados outsiders), lo que, a su vez, acarrea dos graves inconvenientes: se disminuye la competencia presidencial y se favorece el desarrollo del personalismo. Como mostraron los ganadores en las elecciones presidenciales del Brasil en 1989 y Perú en 1990, los particulares pueden crear partidos para luchar por la presidencia y a menudo mantienen tenues vínculos con sus partidos. Este problema se agudiza si el sistema de partidos es débil y si las elites del partido no controlan el proceso de selección de los candidatos presidenciales ${ }^{12}$.

La práctica demuestra que la elección para designar al presidente es la que mayor importancia reviste, hasta el punto en el cual el resultado de ésta puede llegar a "arrastrar" la de los demás cargos electivos, espe-

12 Waldino Suárez, “El Poder Ejecutivo en América Latina...», op. cit., pp. 131 134 y Scott Mainwaring, "Presidencialismo, multipartidismo y democracia: la difícil combinación", Revista de Estudios Políticos, N88, 1995, p. 125. 
cialmente si ambas elecciones, las del Ejecutivo y las del Parlamento, se celebran simultáneamente ${ }^{13}$.

Junto a esto, se ha demostrado que el sistema funciona cuando el Poder Ejecutivo y Legislativo trabajan en armonía porque sus titulares pertenecen al mismo partido. Cuando esto no es así, y ambos poderes están controlados por distintos partidos, sólo un acuerdo fundamental en los asuntos más importantes pueden hacer prosperar al sistema ${ }^{14}$. De lo contrario, puede desembocarse en una situación de inmovilismo y conflicto entre Ejecutivo y Legislativo nociva para la estabilidad de la democracia. Así, en el caso latinoamericano, la forma de gobierno adoptada ha tenido un resultado negativo, si lo analizamos desde esta perspectiva. El presidencialismo latinoamericano se enfrenta a una realidad pluralista desde el punto de vista ideológico, económico y social, que conduce al bloqueo recíproco entre Ejecutivo y Legislativo al no coincidir la ideología mayoritaria en uno y en otro. $Y$ es que, como ya planteó Linz en "Democracy, Presidential or Parlamentary: does make a difference?", ¿quién está mejor legitimado en nombre del pueblo: el Presidente, Jefe de Gobierno, quien es también Jefe del Estado y símbolo de la unidad de la nación, quien ha sido elegido directamente y tiene la sensación de haber sido nombrado representante de todo el pueblo, o la mayoría del Congreso, que se opone a su política?. En un sistema de legitimidad dual -responde- no existe principio democrático alguno que ayude a decidir quién representa en principio la voluntad del pueblo.

Frente a dichas situaciones de bloqueo no existen arbitrarios mecanismos jurídicos destinados a ponerles fin. El Presidente, ante el rechazo sistemático de sus propuestas por el Congreso, no puede acudir a su disolución y el Congreso no puede hacer frente a un Presidente impo-

13 Una confirmación puede encontrarse en el caso de la influencia de las elecciones presidenciales sobre los procesos senatoriales en Estados Unidos.

14 Tal sería el caso de Estados Unidos, donde el consenso económico-social es la base sobre la que descansa el funcionamiento de aquel sistema, y es que su peculiar cultura política permite la formación de mayorías parlamentarias coyunturales que el Presidente puede utilizar para pactar la realización de su programa político. Así lo afirman Waldino Suárez, "El Poder Ejecutivo en América Latina...», op. cit., p. 138 y Eduardo Vírgala Foruria, "La forma de gobierno semiparlamentaria como alternativa a la presidencial y a la parlamentaria", Revista de Estudios Políticos, $\mathrm{N}^{\circ} 89$, JulioSeptiembre 1995, pp. 121-123. 
pular o corrupto mediante la moción de censura, a lo sumo puede acudir al procedimiento de impeachment, que se presenta ineficaz al ser un procedimiento judicial, lento y por cargos delictivos. Así las cosas, los presidentes ( $\mathrm{y}$ la oposición) pueden verse tentados a recurrir a mecanismos "extra-constitucionales", a intentar enmiendas constitucionales que acrecienten sus poderes, o, simplemente, a abandonar su programa, dando lugar a un gobierno meramente de gestión e incapaz de resolver los problemas nacionales ${ }^{15}$.

El modo de elección presidencial, sobre la base del sufragio universal, secreto y directo, puede adoptar alguna de las siguientes fórmulas, cuya importancia es indudable, si tenemos en cuenta que un mismo comportamiento electoral se puede traducir en diversos resultados según la fórmula adoptada (dependiendo de la fórmula electoral adoptada podemos encontrarnos con presidentes electos que no ostentan una mayoría real tan amplia como aparentan $)^{16}$ :

- mayoría simple o relativa en una vuelta ${ }^{17}$

- mayoría absoluta en una única vuelta ${ }^{18}$

- mayoría absoluta en la primera vuelta o mayoría simple en una segunda vuelta entre los dos candidatos que más votos hayan obtenido ${ }^{19}$

15 Humberto Nogueira Alcalá, "I Regimi Presidenziali...", op. cit., pp. $512-522$ y Eduardo Vírgala Foruria, "La forma de gobierno semiparlamentaria...", op. cit., p. 124. Sobre Presidencialismo, multipartidismo e inmovilismo, más detalladamente, Scott Mainwaring, "Presidencialismo, multipartidismo y democracia...», op. cit., pp. 130 a 136.

16 No obstante, la Constitución argentina de 1853 optó por el sistema indirecto, semejante al vigente en Estados Unidos, que rigió hasta Agosto de 1972, cuando la Junta de Comandantes en Jefe aprobó una reforma constitucional con base en la cual el futuro Presidente sería elegido por el pueblo. Maurice Duverger, Instituciones Políticas y Derecho Constitucional, Ariel, Barcelona, 1980, (6ª edición), pp. 609-610.

17 Artículos $172^{\circ}$ de la Constitución de Panamá, $230^{\circ}$ de la Constitución de Paraguay, $151^{\circ}$ de la Constitución de Uruguay y $183^{\circ}$ de la Constitución de Venezuela.

18 Artículo $74^{\circ}$. de la Constitución de Ecuador.

19 Artículos $77^{\circ}$ de la Constitución de Brasil, $190^{\circ}$ de la Constitución de Colombia, $26^{\circ}$ de la Constitución de Chile, $184^{\circ}$ párrafo segundo de la Constitución de Guatemala, $111^{\circ}$ de la Constitución de Perú. La Constitución argentina (artículos $94^{\circ}$ a $98^{\circ}$ ), la de Costa Rica (artículo $138^{\circ}$ ) y la de Nicaragua (artículos $146^{\circ}$ y $147^{\circ}$ ) no exigen mayoría absoluta en la primera vuelta sino la obtención de más del cuarenta y cinco por ciento de los votos afirmativos válidamente emitidos. 
- segunda vuelta parlamentaria ${ }^{20}$

Con ello queda confirmada la tesis de Lijphart, que afirma que el presidencialismo muestra una fuerte tendencia hacia la democracia mayoritaria. El hecho de que una elección presidencial implique casi siempre la elección de una persona, significa que la representación proporcional no puede ser usada. Las únicas posibilidades que restan son los métodos de mayoría absoluta y relativa -como acabamos de constatar-. Para este autor, este tipo de competencia, en el que el ganador se lo lleva todo, genera aún más división y potencia el conflicto ${ }^{21}$.

\subsection{Presidencialismo y sistema de partidos}

Con relación a la elección presidencial no sólo es relevante la fórmula electoral por la que se opte, sino que la forma y el funcionamiento mismo del presidencialismo se verán influidos por el tipo de sistema de partidos y el poder de los grupos de presión ${ }^{22}$.

Por regla general, en el sistema parlamentario o bien existe un partido dominante o bien existe un consenso general tendente a la formación de coaliciones. Y ello porque los gobiernos son responsables ante el Parlamento y es conveniente formar un Ejecutivo estable. Sin embargo, no ha de ser así en el sistema presidencial, pues el Ejecutivo no cae por falta de mayoría en el Congreso que apoye al Presidente. Además, en materia de elecciones presidenciales no importa demasiado la organización efectiva del partido, sino quién es elegido Presidente. Los candidatos sólo necesitan de un voto preciso en un momento determinado. Para lograrlo se rodearán de una compleja red de colaboradores

20 Artículo $90^{\circ}$ de la Constitución de Bolivia, modificado por la Ley de Reforma a la Constitución Política del Estado No 1585, de 12 de Agosto de 1994.

21 Arend Lijphart, "Presidenzialismo e democrazia maggioritaria", Rivista Italiana di Scienza Politica, a. XIX, núm. 3, Diciembre de 1989, pp. 367-384.

22 Scott Mainwaring, "Presidencialismo, multipartidismo y democracia...", op. cit., p. 117 y Mario D. Serrafero, "Presidencialismo y reforma política en América Latina", op. cit. pp. 230-231. También puede estudiarse esta cuestión de forma más detallada, referida a países concretos, así puede consultarse, por ejemplo: $M^{\mathrm{a}}$ Esther del Campo, "Unas notas sobre el sistema de partidos en Chile y Argentina en tiempos de crisis", Revista de Estudios Políticos, núm. 74, Octubre-Diciembre 1991, pp. 177 $-210$. 
que pueda facilitarle ese voto. La organización del partido se centrará, básicamente, en torno a la figura del candidato, los diputados y senadores no son de gran relevancia ${ }^{23}$. El hecho de que candidatos populares puedan acceder a la presidencia con base en el apoyo de partidos débiles o creados expresamente para la ocasión, conduce a la posterior falta de apoyo del presidente en la asamblea legislativa.

La experiencia ha demostrado que en un régimen presidencial el bipartidismo (two-party system) asegura la estabilidad democrática, mientras que el sistema multipartidista acentúa el peligro de inestabilidad y, en el caso de existencia de un partido hegemónico, hace incrementar el riesgo de prácticas autoritarias ${ }^{24}$.

23 Sobre la desorganización de los sistemas de partidos, Waldino Suárez, «El Poder Ejecutivo en América Latina...., op. cit., pp. 134-134. Una sucinta caracterización de los partidos políticos en Iberoamérica puede encontrarse en Maurice Duverger, Instituciones Políticas y Derecho Constitucional, op. cit., pp. 618-619. Ya de forma más detallada, Manuel Alcántara, Ismael Crespo y Antonia Martínez, (comps.), Partidos y elecciones en América Latina. Guía bibliográfica, Ed. AIETI/Síntesis, Madrid, 1992. Esta guía recopila una serie de estudios sobre partidos políticos y elecciones en América Latina y trata de ofrecer una visión panorámica de la evolución del sistema polírico en cada uno de los países propuestos.

24 Scott Mainwaring argumenta que la combinación de presidencialismo y multipartidismo hace que las democracias estables sean difíciles de mantener. En su artículo examina el pobre récord del presidencialismo para mantener la democracia durante, al menos, 25 años consecutivos. Sólo cuatro (Colombia, Costa Rica, Venezuela y Estados Unidos) de treinta y una democracias estables, tienen sistemas presidenciales. Pese a que han existido muchos intentos de construir la democracia sobre la base de la combinación del presidencialismo con un sistema multipartidista, únicamente Ecuador se nos presenta como la democracia de mayor permanencia-desde 1979, y no exenta de problemas- con esta combinación. Para él la respuesta que explica el porqué de esa difícil combinación (multipartidismo/presidencialismo) es triple: en los sistemas presidenciales el multipartidismo incrementa la probabilidad de polarización ideológica; con el multipartidismo, los Presidentes necesitan construir coaliciones interpartidistas para obtener medidas a través del Legislativo, pero la construcción de coaliciones interpartidistas en los sistemas presidenciales es más difícil y menos estable que en los sistemas parlamentarios. El logro de la estabilidad democrática, concluye, pasa por una de estas dos soluciones: cambiar de un sistema presidencial a uno semipresidencial o parlamentario, o bien tomar medidas para reducir la fragmentación del sistema de partidos. Scott Mainwaring, "Presidencialismo, multipartidisimo y democracia: la difícil combinación", op. cit., pp. 115 a 144. También, Waldino Suárez, “El Poder Ejecutivo en América Latina...», op. cit., pp. 134 a 140 y Mario D. Serrafero, "Presidencialismo y reforma política en América Latina", op. cit., pp. 230-231. 
Por lo que a las coaliciones interpartidistas se refiere, también la combinación multipartidismo/sistema presidencial dificulta su formación y estabilidad, y ello porque en los sistemas presidenciales los partidos de la coalición se encuentran menos firmemente comprometidos a proporcionar apoyo al gobierno y los incentivos para romper las coaliciones son generalmente mayores, mientras que en los sistemas parlamentarios los partidos eligen al gabinete y a los primeros ministros y son responsables de proporcionar apoyo al gobierno ${ }^{25}$. De hecho hay autores que resaltan el carácter «contramayoritario» del sistema presidencial $^{26}$.

Independientemente del sistema de partidos que rija en los Estados latinoamericanos, lo cierto es que, generalmente, se constata un deficiente cumplimiento de las funciones de representación política (expresión, canalización y comunicación de las demandas de la sociedad). ${ }^{27}$

25 Waldino Suárez, «El Poder Ejecutivo en América Latina...», op. cit., pp. 134135 y Scott Mainwaring, "Presidencialismo, multipartidismo y democracia...", op. cit., pp. 117 y $137-138$.

26 Así, Gargarella entiende que un sistema puede calificarse como contramayoritario cuando nos encontramos ante un ordenamiento institucional que tenga entre sus principales fines el de obstaculizar la formación, expresión y puesta en práctica de la voluntad de las mayorías. Afirma que la generalidad de los países latinoamericanos se encuentran regidos por ordenamientos constitucionales abiertamente contramayoritarios y que el sistema presidencialista en ellos establecido define decisivamente dicho carácter contramayoritario. Precisamente contar con este esquema de organización política ha perjudicado enormemente las posibilidades de lograr un consenso entre las principales agrupaciones políticas de cada país. La posibilidad de acuerdos más efectivos queda reducida a dos casos: el acuerdo entre las fuerzas políticas tendentes a sobrevivir ellas frente a cualquier salida de corte autoritario y los pactos de alternancia. Roberto Gargarella, «El Presidencialismo como sistema contramayoritario", en Nino y otros, El Presidencialismo puesto a prueba, op. cit., pp. 81 - 105. En el mismo sentido que apuntamos, Arend Lijphart, "Presidenzialismo e democrazia maggioritaria...n, op. cit.

27 Sartori establece que las funciones básicas de los partidos políticos serían la de representación y la de expresión y canalización de los intereses particulares frente al Estado. Giovanni Sartori, Partidos y Sistemas de Partidos, Madrid, Alianza Editorial, 1980. 


\section{Poderes y limitaciones de los presidentes latinoamericanos}

\subsection{Poderes}

Pese a la indudable influencia que la Constitución de los Estados Unidos ha podido ejercer sobre las constituciones iberoamericanas, no cabe duda que existen diferencias entre ellas. Precisamente un capítulo en el que se evidencian estas diferencias viene constituido por los poderes de los Presidentes latinoamericanos. La comparación en materia de poderes entre las constituciones presidencialistas latinoamericanas y la de los Estados Unidos pone de manifiesto que la última otorga al Poder Ejecutivo menos atribuciones que aquéllas. El plus de poderes que tienen reconocidos los presidentes latinoamericanos en relación con el modelo presidencial estadounidense puede reconducirse a dos grandes categorías: las competencias legislativas (por ejemplo, iniciativa presidencial en materia de ley, la delegación de facultades legislativas, veto parcial, etc.) y los denominados poderes extraordinarios o de crisis.

\subsubsection{Competencias legislativas}

A diferencia de lo que ocurre con el Presidente de los Estados Unidos, en Iberoamérica el Presidente de la República es presentado en los textos constitucionales como un órgano colegislador ${ }^{28}$. Así los presidentes latinoamericanos tienen conferidas las atribuciones que a continuación pasamos a relacionar:

\subsection{1.a Iniciativa legislativa}

Es prácticamente unánime en la doctrina la opinión de que la iniciativa legislativa en manos de los presidentes iberoamericanos les permite orientar la labor legislativa del Parlamento con arreglo a las prioridades

28 Como ya se ha estudiado, la Constitución estadounidense atribuye al Congreso, con la colaboración del Presidente, por medio de la institución del veto (Artículo $1^{\circ}$, Sección 7), la titularidad de la función legislativa federal (Artículo $1^{\circ}$, Sección 1), sin pronunciarse expresamente sobre la posibilidad de la iniciativa legislativa presidencial, salvo lo recogido en el primer inciso del Artículo $1^{\circ}$, Sección 7 con relación a la materia de impuestos y tributos, o sobre el ejercicio de la potestad reglamentaria. 
de sus respectivos programas de gobierno, siempre que, claro está, cuenten con el suficiente apoyo parlamentario ${ }^{29}$.

Dentro de la facultad de iniciativa legislativa, determinados textos constitucionales prevén, respecto de determinadas materias, el ejercicio de una iniciativa legislativa exclusiva por parte del Presidente ${ }^{30}$. Aun-

29 A título de ejemplo, véase Humberto Nogueira, «I Regimi Presidenziali...", op. cit. p. 495. Sin embargo, Krsticevic mantiene que la facultad de presentar proyectos de ley al Parlamento no es determinante en el predominio del Poder Ejecutivo. Como argumentos que avalan su postura alude a la amplitud de sujetos que en algunas Constituciones tienen abierta la posibilidad de ejercitar la iniciativa legislativa; además, el ejercicio de la iniciativa legislativa presidencial ni obstaculiza el ejercicio de la misma por parte del Poder Legislativo, ni impide la posibilidad de rechazar, aprobar o modificar los proyectos presidenciales; tampoco la calificación de un proyecto como urgente por parte del Poder Ejecutivo impide la aprobación o modificación del proyecto; incluso el posible desequilibrio que podría suponer la atribución en exclusiva al Poder Ejecutivo de la iniciativa legislativa en determinadas materias (principalmente, presupuesto u organización administrativa del Estado), es acotado razonablemente por la posibilidad de no aprobar o modificar el proyecto presentado. Viviana Krsticevic, "Presidencialismo en América Latina», op. cit. pp. 135-136. Esta atribución está recogida en los artículos $77^{\circ}$ de la Constitución de Argentina, $61^{\circ}$ y $84^{\circ}$ III de la Constitución de Brasil, $65^{\circ}$ de la Constitución de Ecuador, $164^{\circ}$ y $183^{\circ} \mathrm{g}$ ) de la Constitución de Guatemala, 71.I de la Constitución de México, 140.2 y 150.3 de la Constitución de Nicaragua, $203^{\circ}$ y 238.12 de la Constitución del Paraguay, $107^{\circ} \mathrm{de}$ la Constitución del Perú y $162^{\circ}$ Segundo de la Constitución de Venezuela. Los textos constitucionales de Bolivia (artículo $71^{\circ}$ ) y Chile (artículos $62^{\circ}$ y $65^{\circ}$, modificado por el Artículo único No $36^{\circ}$ de la Ley de Reforma Constitucional No 18.825, de 17 de Agosto de 1989) especifican que la iniciativa del Presidente tendrá su origen en un mensaje del mismo. En cuanto a Colombia (artículos $154^{\circ}$ y 200.1), Costa Rica (artículos $123^{\circ}$ y 140.5 ) y Uruguay (artículo $133^{\circ}$ párrafo primero), ha de puntualizarse que la iniciativa legislativa se atribuye al Poder Ejecutivo, quien podrá presentar los correspondientes proyectos por medio de los Ministros. En Colombia, el Presidente de la República solamente podrá dictar decretos-leyes en caso de necesidad o de conveniencia pública (artículo 150.10 de la Constitución).

30 Así, los artículos $96.7^{a}$ y $147^{\circ}$ de la Constitución de Bolivia; 140.15 de la de Costa Rica; 183.j) de la de Guatemala; 150.5 (según reforma aprobada en la Ley 192, publicada el 4 de Julio de 1995) del texto de Nicaragua; $78^{\circ}$ de Perú y $228^{\circ}$ de Venezuela, disponen que corresponde al Presidente de la República presentar, ante el Legislativo, los Presupuestos de la Nación. Ahora bien, en el caso de Costa Rica, dicha labor no es exactamente exclusiva del Presidente, sino que corresponde conjuntamente al Presidente y al respectivo Ministro de Gobierno, si bien la preparación del proyecto ordinario corresponde a un departamento ejecutivo especializado en la materia, cuyo jefe scrá nombrado por el Presidente de la República (véase el artículo $177^{\circ}$ de 
que esta atribución permite orientar el gasto y la economía del país ${ }^{31}$, no debe perderse de vista que el poder de aprobar los impuestos es, y en ello coincide prácticamente toda la doctrina, una de las facultades legislativas más centralizadoras y, por ende, el arma más eficaz con que cuenta el Congreso frente a la presidencia. A ello hay que unir que suele dejarse poco espacio de maniobra al presidente para llevar a cabo la transferencia de fondos, para lo que se exige en algunas constituciones la mayoría de dos tercios en el Congreso. En esta exigencia Suárez detecta un posible motivo de colapso en la administración. Semejante consecuencia puede acarrear la previsión, recogida en algunas constituciones, en virtud de la cual si el Presupuesto anual no se vota a tiempo, se pone automáticamente en práctica el Presupuesto del año anterior, lo que, en países donde la tasa de inflación es demasiado alta, puede significar que el Presidente cuenta con tres cuartos o incluso la mitad de los fondos de los que disponía el año anterior ${ }^{32}$.

la Constitución). En similares términos, respecto a la participación del Ministro respectivo, se pronuncian el artículo $74^{\circ}$, párrafo cuarto de la Constitución mexicana, el artículo 179.7 de la Constitución panameña y el artículo 168.19 de la Constitución de Uruguay. Precisamente, la Constitución de Uruguay (artículos $86^{\circ}$ y $214^{\circ}$ ) prevé que en la Ley de Presupuestos se incluirá la creación y supresión de empleos y servicios públicos; la fijación y modificación de dotaciones y la autorización para los gastos, con lo que, podemos concluir, estas materias también son de iniciativa exclusiva del Ejecutivo. Por último, hemos de precisar que en algunos textos constitucionales se prevén mecanismos para suplir la posible omisión del Poder Ejecutivo (véase, por ejemplo, el artículo 171.b) de la Constitución de Guatemala). Por lo que a la Constitución estadounidense se refiere, ésta no atribuye explícitamente a ningún órgano la tiltularidad del poder para disponer del gasto público y aprobación del Presupuesto.

31 El artículo $70^{\circ}$ de la Constitución de Ecuador encomienda a la función Ejecutiva la formulación de la proforma del Presupuesto del Estado, quedando en manos del Congreso la aprobación definitiva del mismo.

32 Véase Waldino Suárez, «El Poder Ejecutivo en América Latina...», op. cit., pp. 141-142. Además de la materia tributaria, el artículo $61^{\circ}$, parágrafo 1 de la Constitución brasileña confía a la iniciativa exclusiva del Presidente la fijación o modificación de los efectivos de las Fuerzas Armadas, así como lo relativo a organización administrativa, judicial y de determinadas instituciones públicas y a los empleados y funcionarios públicos y su régimen jurídico. Según el artículo $154^{\circ}$ de la Constitución de Colombia quedan reservadas a la iniciativa del Gobierno las leyes que hacen referencia a:

- El Plan Nacional de desarrollo y de inversiones públicas; el establecimiento de las rentas nacionales y gastos de la Administración; el crédito público; las órdenes de 


\subsection{1.b La babilitación legislativa}

Otra de las facultades legislativas que competen a algunos presidentes latinoamericanos, no a todos, es la habilitación legislativa, en virtud de la cual se permite que el Poder Ejecutivo asuma la función legislativa ${ }^{33}$.

La extensión de las facultades que ostenta el presidente con base en la habilitación legislativa varía de unas regulaciones a otras. Así, en unos casos se le va a permitir dictar decretos-leyes necesarios para enfrentar una situación de emergencia o excepcional (artículo 99.3, párrafo tercero de la Constitución de Argentina), en otros se le va a permitir dictar medidas económicas (Venezuela, artículo $190^{\circ}$ Octavo de la Constitución), etc. También es variable la intensidad del control a que es sometido el ejercicio de las facultades legislativas conferidas, si bien, de forma genérica, puede decirse que la mayoría de las Constituciones establece un sistema de garantía del uso correcto de estas facultades a través de controles ejercidos fundamentalmente por el Parla-

parricipaciones en las rentas nacionales o transferencias de las mismas y las exenciones de impuestos, contribuciones o tasas nacionales.

- La estructura orgánica de la Administración; el régimen salarial de los empleados públicos y miembros del Congreso Nacional y Fuerzas Armadas y la creación y funcionamiento de las corporaciones Autónomas Regionales.

- La creación o autorización de empresas industriales y comerciales del Estado y las autorizaciones de aportes o suscripciones del Estado a empresas industriales o comerciales.

- La regulación del comercio exterior y régimen de cambio internacional.

- El Banco de la República y las funciones de su Junta Directiva.

Por último, la Constitución chilena, junto a la presentación ante el Congreso de la Ley de Presupuestos (artículo 64\%), atribuye al Presidente la iniciativa de los proyectos de ley relacionados con la alteración política o administrativa del país, la administración financiera y presupuestaria, la enajenación de bienes del Estado y los municipios y las Fuerzas Armadas (artículo $62^{\circ}$, párrafo tercero), la responsabilidad financiera del Estado, los impuestos, la contratación colectiva, la seguridad social, etc.

33 En Estados Unidos únicamente existe un poder reglamentario del Presidente. Por lo que Iberoamérica se refiere, hemos encontrado disposiciones que privilegian al Poder Ejecutivo frente al Legislativo en resolución de determinadas cuestiones en textos constitucionales como: Argentina (artículo 99.3), Brasil (artículos $62^{\circ}, 68^{\circ}$ y 84.XXV), Colombia (artículo 150.10), Ecuador (artículo 65), Guatemala (artículo $183^{\circ} \mathrm{f}$ ), Panamá (artículo 153.16) y Venezuela (artículo $190^{\circ}$ octavo). Otras Constituciones, como la de Costa Rica, prohiben expresamente este tipo de facultad (artículos $9^{\circ}$ y $\left.10^{\circ}\right)$. 
mento: se exige delegación previa del Congreso y dar cuenta de inmediato al mismo, que puede desaprobar las medidas adoptadas revocándolas o modificándolas.

\subsection{1.c La legislación delegada}

La delegación de facultades legislativas se entiende como un traslado de funciones legislativas, por parte del titular nato de las mismas, en favor del órgano ejecutivo. Esta posibilidad viene contemplada en algunos de los textos constitucionales latinoamericanos, con base en los cuales se permite al Presidente de la República legislar por decreto durante un período de tiempo suficientemente amplio y en las materias que permita la Constitución y que sean autorizadas por el Parlamento $^{34}$.

34 Así el artículo $76^{\circ}$ de la Constitución argentina sólo permite la delegación en materia de "administración o de emergencia pública» dentro del plazo y bases establecidas por el Congreso, mientras que el artículo $190^{\circ}$ Octavo de la Constitución venezolana admite la delegación en "materia económica y financiera cuando así lo requiera el interés públicom. En Brasil (artículo $68^{\circ}$ de la Constitución), una resolución del Congreso Nacional será la que delimite el contenido y los términos del ejercicio de la delegación, posibilidad que queda vedada en relación a los actos de competencia exclusiva del Congreso Nacional, los de competencia privativa de la Cámara de Diputados o del Senado Federal, la materia reservada a ley complementaria, así como la legislación referente a una serie de objetos tasados (Poder Judicial, nacionalidad y ciudadanía, derechos...). La Constitución chilena (artículos 32.3 y $61^{\circ}$ ), siguiendo el precedente del texto de 1925, introduce la posibilidad de que sea el Presidente de la República quien solicite la delegación. De nuevo dicha delegación se presenta delimitada en cuanto a su objeto, pues no podrá extenderse a la nacionalidad, ciudadanía, elecciones, plebiscito, materias comprendidas en las garantías constitucionales, las que deban ser objeto de leyes orgánicas o de quórum cualificado. De forma similar, en Perú «no pueden delegarse las materias que son indelegables a la Comisión Permanente" (artículo $104^{\circ}$ de la Constitución). Por contra, la Constitución estadounidense no recoge expresamente la posibilidad de la delegación legislativa, pero tampoco la prohibe expresamente. Un análisis detallado de la delegación legislativa en la Constitución de Venezuela, puede encontrarse de la mano de Domingo Alfonso Bacalao Octavio, "El fortalecimiento del Ejecutivo y la delegación legislativa», op. cit., pp. 83121. Según este autor, los términos económicos y financieros a que alude el precepto constitucional abren un inmenso campo para la actuación del órgano administrativo, lo cual se encuadra dentro de las «modernas tendencias del derecho constitucional". Nosotros nos decantamos más por la tesis que defiende que, tal y como se dispone en 
Así, tras el análisis de los distintos preceptos constitucionales, podemos sostener que la delegación legislativa supone una habilitación, regulada constitucionalmente en Iberoamérica, del Poder Ejecutivo para poder ejercitar la función legislativa, y que representa una nueva forma de ejercer la potestad legislativa, especialmente en las esferas del Derecho administrativo y financiero.

\subsection{1.d El veto}

Una modificación importante introducida por el constitucionalismo iberoamericano respecto al modelo norteamericano consiste en la posibilidad de que el presidente ejerza no sólo el veto total sino también el parcial. Diversos países iberoamericanos han atribuido al Presidente de la República el poder de veto suspensivo parcial (o item veto) sobre los proyectos de leyes aprobados por el Congreso. La modalidad de veto parcial permitiría al presidente enmendar o eliminar alguna o algunas partes del proyecto de ley aprobado por el Parlamento, y presentado a él para su promulgación, y conservar aquellas otras partes que pudiesen resultar útiles para el desarrollo del programa presidencial, lo cual no sería posible mediante el rechazo total del proyecto ${ }^{35}$. El proyecto se devuelve con las observaciones a la Cámara de origen o las cámaras reunidas en asamblea, que examinan dichas observaciones. El veto presidencial puede ser superado por una mayoría absoluta (Brasil, Colombia, Nicaragua, Paraguay y Perú) de tres quintos (Uruguay, cuando nos encontramos ante el ejercicio del veto total) o de dos tercios (Argentina, Ecuador, México y Panamá). Si no se llega a un acuerdo de las cámaras, ni para insistir en el proyecto original, ni para aprobar las

el tenor de los preceptos constitucionales, la facultad legislativa material del Ejecutivo debe reservarse para casos de crisis generalizada y vetada a determinadas materias.

35 Así las cosas, podemos afirmar que los Presidentes iberoamericanos gozan de una mayor libertad que el Presidente de los Estados Unidos, ya que éste sólo tiene conferido el poder de veto total, con la consecuencia de que puede ocurrir que el Congreso introduzca el texto de un proyecto de ley un conjunto de disposiciones que, al ser necesarias y urgentes para la política presidencial, obliguen al Presidente a aprobar la totalidad del proyecto, donde, además, se recogen otras disposiciones que de haber ido en textos distintos y separados habrían sido rechazadas por el Presidente. Un ejemplo de veto absoluto podemos encontrarlo en el artículo $79^{\circ}$ de la Constitución de Paraguay de 1969. 
observaciones, se archiva el proyecto y queda vedado su tratamiento hasta el siguiente período legislativo ${ }^{36}$.

Mención especial merece el artículo $173^{\circ}$ de la Constitución de Venezuela, que prevé la posibilidad de un veto doble ${ }^{37}$.

36 Esta institución está prevista, a título de ejemplo, en las Constituciones de Argentina (ver artículos $78^{\circ}, 80^{\circ}$ y $83^{\circ}$ ), donde se matiza que las partes no vetadas «solamente podrán ser promulgadas si tienen autonomía normativa y su aprobación parcial no altera el espíritu ni la unidad del proyecto sancionado por el Congreso»; Brasil (artículos $66^{\circ}, 67^{\circ}$ y $84 . \mathrm{V}$ ), con la peculiaridad de que la materia objeto de un proyecto de ley rechazado por el Presidente, solamente podrá constituir objeto de un nuevo proyecto, en el mismo período de sesiones, mediante la propuesta de la mayoría absoluta de los miembros de cualquiera de las Cámaras del Congreso Nacional; Colombia (artículos $166^{\circ}$, que regula los distintos plazos para interponer el veto en proporción a la extensión del proyecto de ley, y 167); Costa Rica (artículos $125^{\circ}$ a $128^{\circ}$ ), donde se prevé que si el veto presidencial se funda en razones de inconstitucionalidad no aceptadas por la Asamblea, ésta enviará el proyecto a la Corte Suprema para que resuelva, por una mayoría de por lo menos dos tercios de sus integrantes, la parte no considerada inconstitucional por la Corte vuelve a la Asamblea; Ecuador (artículos $68^{\circ}, 69^{\circ}$ y 78.b), donde se establece que las leyes objetadas por el Presidente sólo podrán ser consideradas por el Congreso transcurrido un año desde la fecha del veto, si bien cabe la posibilidad de pedir al Presidente que las someta a consulta popular; México (artículo $72^{\circ}$, apartados A, B, C y J); Nicaragua (artículos $142^{\circ}, 143^{\circ}$ y 150.3 ); Panamá (artículos $162^{\circ}$ a $165^{\circ}$ y 178.6 ), texto en el que se ordena que en caso de que la Asamblea Legislativa insistiere en la adopción del proyecto vetado, el Ejecutivo lo pasará a la Corte Suprema de Justicia para que decida sobre su constitucionalidad; Paraguay (artículos $205^{\circ}$ a $209^{\circ}$ y 238.4), que, a su vez, permite la posibilidad del rechazo o aceptación total o parcial, por parte de las Cámaras del Congreso, de las objeciones presentadas por el Presidente; Perú (artículo 108 Uruguay (artículos $137^{\circ}$ a $141^{\circ}, 145^{\circ}$ y 168.6), regulación que establece la publicación en prensa de las objeciones y el resultado de las votaciones referentes a la reconsideración de las mismas por parte de la Asamblea General.

37 El Presidente de la República, dentro del plazo de los diez días con que cuenta para promulgar la ley, puede, con el acuerdo del Consejo de Ministros, pedir al Congreso, mediante exposición razonada, la reconsideración del proyecto de ley que le ha sido presentado, a fin de que se modifique alguna de sus disposiciones o se levante la sanción a toda la ley o a parte de ella (primer veto). Si las Cámaras en sesión conjunta insisten en el texto original por mayoría de las dos terceras partes de los presentes, el Presidente queda obligado a promulgar la ley dentro de los cinco días siguientes a su recibo, sin poder formular nuevas observaciones. Pero si la decisión de mantener el texto original hubiese sido adoptada por mayoría simple, el Presidente puede optar entre promulgar la ley o devolverla al Congreso para una última reconsideración (segundo veto). En este caso, la decisión de las Cámaras en sesión 
Como excepción al veto suspensivo parcial generalizado en Iberoamérica, podemos citar la regulación de la Constitución guatemalteca (artículos $178^{\circ}, 179^{\circ}$ y $183 . \mathrm{h}$ ) donde expresamente se dispone que "las leyes no podrán ser vetadas parcialmente".

Esta participación del presidente en la función legislativa no supone, en absoluto, la privación al Parlamento de su titularidad, pero puede interpretarse como una exigencia a las cámaras de mayor consenso -a la hora de superar el veto- ${ }^{38}$. Ahora bien, en la medida en que nos encontremos ante países en los que es el presidente quien realmente legisla, hemos de concluir que el veto no juega el papel que tiene asignado en el procedimiento legislativo y que es el Poder Legislativo quien ejerce una especie de derecho de veto respecto a las reformas que realiza a los proyectos presidenciales ${ }^{39}$.

\subsection{1.e Otras competencias legislativas}

Además de los poderes normativos estudiados y el derecho de veto, las constituciones iberoamericanas aún confieren al presidente tres poderes más en el ámbito legislativo: la sanción de las leyes, la reunión de las cámaras y el derecho de mensaje.

\section{- La sanción de las leyes}

A la figura del presidente también corresponde la sanción de las leyes, pudiendo adoptar una de estas tres decisiones posibles: sancionar dentro de un plazo determinado, interponer el veto, o no sancionar ni

conjunta será definitiva, aun cuando sea adoptada por mayoría simple, y el Presidente está obligado a promulgar la ley dentro de los cinco días siguientes a su recibo.

38 Así lo pone de manifiesto Toniarti en «El Poder Ejecutivo en los Sistemas presidenciales de gobierno", Revista Vasca de Administración Pública, $N^{\circ} 34$ (II), 1992, p. 206. Krsticevic sostiene que si bien la facultad de veto otorga al Poder Ejecutivo un poder de intervención en el proceso legislativo, no lo obstruye, pues el Legislativo ostenta el poder para insistir en el proyecto original con una mayoría cualificada, y en algunos textos se prevé la intervención del Poder Judicial, cuya actuación garantiza una mayor imparcialidad. Viviana Krsticevic, "Presidencialismo en América Latina", op. cit. p. 138.

39 Así lo apunta Carpizo en relación al caso mexicano, véase Jorge Carpizo, El Presidencialismo Mexicano, op. cit., p. 87. El análisis de las amplias facultades legislativas del Presidente mexicano se encuentran en las pp. 99-109. 
interponer el veto, en cuyo caso, pasado aquel plazo determinado el proyecto se convierte en ley ${ }^{40}$. Por lo tanto, la firma presidencial no puede considerarse, simplemente, como un acto debido, sino que tiene un contenido discrecional.

\section{- Reunión de las Cámaras}

En principio, y por regla general, la reunión del Congreso es automática $^{41}$. Sin embargo, el presidente puede convocarlo para sesiones extraordinarias, e incluso, en algunos casos, prorrogar las sesiones ordinarias ${ }^{42}$.

40 Así tenemos, por ejemplo, lo expresamente previsto en las Constituciones de Brasil, artículo 84.IV; Colombia, donde la sanción compete al Gobierno, artículos $157.4,165^{\circ}, 168^{\circ}$ y 189.9 ; Costa Rica, artículos $124^{\circ}$ y 140.3 , que reservan la sanción a la acción conjunta del Presidente con el Ministro correspondiente; Chile, artículos, $32.1,69^{\circ}$ y $72^{\circ}$; Guatemala, artículos $177^{\circ}$ y $\left.183 . c\right)$; Ecuador, artículo $78 . b$ ); Nicaragua, artículo $141^{\circ}$; Panamá, artículo $160^{\circ}$ y Venezuela, artículo $167^{\circ}$. También al Presidente de los Estados Unidos corresponde la sanción de las leyes (Artículo $1^{\circ}$, Sección 7, parágrafo segundo), pudiendo adoptar una de estas tres posturas posibles: sancionar dentro del término de diez días, interponer el veto, o no sancionar ni interponer el veto, en cuyo caso, pasados los días, y siempre que no estén suspendidas las sesiones de las Cámaras, el proyecto se convierte en ley.

41 Sobre las reuniones ordinarias del Congreso pueden consultarse los artículos $50^{\circ}$ y $63^{\circ}$ de la Constitución de Argentina, $46^{\circ}$ y $60^{\circ}$ de la Constitución de Bolivia, $57^{\circ}$ de la Constitución de Brasil, $138^{\circ}$ de la Constitución de Colombia, $116^{\circ}$ de la Constitución de Costa Rica, $51^{\circ}$ de la Constitución de Chile, $59^{\circ}$ de la Constitución de Ecuador, $158^{\circ}$ de la Constitución de Guatemala, $65^{\circ}$ y $66^{\circ}$ de la Constitución de México, $143^{\circ}$ de la Constitución de Panamá, $104^{\circ}$ de la Constitución de Uruguay y $154^{\circ}$ de la Constitución de Venezuela.

42 Así se dispone en los artículos $63^{\circ}$ y 99.9 de la Constitución de Argentina, $46^{\circ}, 47^{\circ}$ y 96.5 de la Constitución de Bolivia, $57^{\circ}$, parágrafo $6^{\circ}$.II de la Constitución de Brasil, $138^{\circ}$ y 200.2 de la Constitución de Colombia, $118^{\circ}$ y 140.14 de la Constitución de Costa Rica (si bien, hemos de advertir que la convocatoria por parte del Presidente de la República se hará conjuntamente con el respectivo Ministro del Gobierno), 32.2 y $52^{\circ}$ de la Constitución de Chile, $64^{\circ}$ de la Constitución de Ecuador, $158^{\circ}$ y 183 l) de la Constitución de Guatemala, 89 .XI de la Constitución de México, 150.7 de la Constitución de Nicaragua, $143^{\circ}$ y 178.4 de la Constitución de Panamá, $184^{\circ}$ y 238.11 de la Constitución de Paraguay, 118.6 de la Constitución de Perú $104^{\circ}$ y 168.8 de la Constitución de Uruguay y $190.9^{\circ}$ de la Constitución de Venezuela. En el caso de los Estados Unidos, la reunión del Congreso es automática, debiendo celebrarse una vez por año y fijando la Constitución el 3 de enero como fecha de comienzo de las reuniones, durando el mandato de los representantes hasta 


\section{- Los mensajes}

Por lo que a la actividad informativa se refiere, hemos de señalar que el mensaje anual sobre el estado de la República se presenta personalmente ante las cámaras. Independientemente de la parte reservada a resumir las principales actividades de la administración, no cabe duda de que el informe contiene un mensaje político en el que se perfilan las directrices a seguir y las medidas a adoptar para hacer efectivo el programa político presidencial ${ }^{43}$.

\subsubsection{Los poderes extraordinarios o de crisis}

Como la experiencia ha demostrado en numerosas ocasiones, existen determinadas situaciones extraordinarias en las que la existencia del orden constitucional o la seguridad y bienestar de los miembros de la comunidad estatal se ponen en peligro. En tales situaciones, las disposiciones constitucionales de aplicación "normal» sobre relaciones entre poderes y protección de derechos devienen insuficientes y se hace imprescindible la búsqueda de un remedio que solvente la situación de emergencia. Una de las fórmulas que se arbitra al efecto consiste en encomendar, expresamente en la Constitución, al Poder Ejecutivo que tome las medidas oportunas para enfrentarse con las amenazas al orden constitucional. Otro método consiste en la determinación de unos estados excepcionales en los que los poderes públicos (principalmente el Poder Ejecutivo, dada su mayor agilidad) pueden asumir competencias predeterminadas en la Constitución o en la ley ${ }^{44}$. Los denomina-

el 3 de Enero del segundo año (Artículo I, Sección 2 y Enmienda XX). Pero el Presidente de los Estados Unidos puede convocar a ambas Cámaras o cualquiera de ellas para sesiones extraordinarias y fijar el plazo de su vacación cuando aquéllas no se pongan de acuerdo (Artículo II, Sección 3).

43 En relación con esta facultad consúltese los siguientes preceptos constitucionales: Argentina, 99.8; Bolivia, 96.10; Brasil, 84.XI; Colombia, 189.12; Costa Rica, 139.4; Chile, $62^{\circ}$ y $65^{\circ}$; Guatemala, 183.1; Ecuador, 78.o); México, $69^{\circ}$; Nicaragua, 138.16; Panamá, 178.5; Paraguay, $184^{\circ}, 202.15$ y 238.8; Perú, 118.7; Uruguay, 168.5 y Venezuela, $190^{\circ}$ Vigésimo y $191^{\circ}$.

44 Sobre las vías constitucionales de tratamiento de las situaciones de emergencia, véase Luis López Guerra, "Derechos Fundamentales y Estados de Excepción”, La Corte y el Sistema Interamericanos de Derechos Humanos, Rafael Nieto Navia Editor, San José, Costa Rica, 1994, pp. 279-283 . 
dos poderes de crisis permiten al Presidente de la República suspender determinadas garantías constitucionales y adoptar las medidas necesarias para asegurar la continuidad de la política gubernamental, así como actuar como órgano legislativo ejercitando competencias propias del Congreso $^{45}$. Los ordenamientos iberoamericanos contienen una amplia diversidad de denominaciones estado de emergencia, (estado de sitio, estado de defensa, etc.) y soluciones con relación a los supuestos excepcionales y a las consecuencias que de ellos derivan. La cuestión estriba en determinar cuáles son las circunstancias excepcionales que legitiman al Presidente irrogarse aquellos poderes. La determinación de dichos supuestos desencadenantes se suelen fijar en la Constitución y en la normativa interna de los Estados (así, podemos aludir a situaciones de anormalidad social, de alteración política, de ataque exterior...). En definitiva, la heterogeneidad del sistema iberoamericano aconseja un estudio particular de los distintos Estados en lo relativo a esta cuestión que no podemos llevar a cabo en este trabajo. Asimismo, advertimos que somos conscientes de que un estudio pormenorizado de las situaciones de emergencia y la protección de derechos en Latinoamérica habría de realizarse no sólo sobre la base del estudio de la normativa constitucional y/o legislativa existente en los Estados, sino que tendría también que prestarse atención a la labor de los jueces y a la labor

45 Humberto Nogueira Alcalá, "I Regimi Presidenziali...», op. cit., p. 499. De hecho, la profusión en el uso del expediente técnico del Gobierno determina que la declaración de emergencia en Iberoamérica se salde como una situación de normalidad constitucional, a diferencia de lo que ocurre con los sistemas excepcionales europeos, donde ésta supone una verdadera derogación del régimen constitucional. Ahora bien, ha de advertirse que si bien la autoridad competente para declarar los estados de excepción suele ser el Presidente de la República, en ocasiones se requiere que dicha declaración se complemente con el acuerdo de otros órganos (por ejemplo, en Chile el Presidente de la República con el acuerdo del Consejo de Seguridad Nacional). Véase, Domínguez Zorrero, Manuel, «Estados excepcionales y garantías de derechos fundamentales en Latinoamérican, Revista de Estudios Políticos, número 81, JulioSeptiembre 1993, pp. 267 y 269. Por su parte, Krsticevic sostiene que los poderes atribuidos al Poder Ejecutivo en función de la declaración de estados excepcionales encuentran límites en las facultades del Congreso de revocar y controlar, en los límites temporales a los que se someten y en la intervención del Poder Judicial que se arbitran en los distintos textos. "Creemos por lo expuesto -concluye- que esta característica tampoco provoca un desbalance del sistema de gobierno». Viviana Krsticevic, "Presidencialismo en América Latina», op. cit., p. 141. 
realizada por la jurisdicción internacional americana a través de la Corte Internacional de Justicia, mas este no constituye el objeto central de nuestra exposición ${ }^{46}$.

Por su parte, el ordenamiento jurídico constitucional del Ecuador que regula el régimen de excepción se enmarca en los principios que han conformado al constitucionalismo de América Latina. No obstante, en la actual Constitución del Ecuador se introducen elementos nuevos que suponen un avance: al tiempo que se posibilita al Ejecutivo actuar de forma ágil y rápida conforme a las circunstancias, éste es objeto de control por parte de otros órganos del Estado para evitar una utilización indebida o extralimitación en el uso de las facultades extraordinarias ${ }^{47}$.

Por último, es obligada la referencia a la Constitución de Costa Rica que atribuye a la Asamblea Legislativa la suspensión de los derechos y garantías individuales consignados en los artículos $22^{\circ}$ a $24^{\circ}, 26^{\circ}, 28^{\circ}$ a $30^{\circ}$ y $37^{\circ}$. El Ejecutivo queda obligado a rendir cuentas a la Asamblea -en su próxima reunión- de las medidas tomadas para salvar el orden público o mantener la seguridad del Estado (artículo 121.7). Únicamente en caso de receso de la Asamblea Legislativa corresponde al Presidente de la República, y al respectivo ministro de gobierno, decretar la suspensión de derechos y garantías a que se refiere el número 7

46 Como ejemplo ilustrativo de poderes extraordinarios podemos atender a la extensa regulación chilena (artículos $39^{\circ}$ a $41^{\circ}$ de la Constitución) donde, tras determinar que es atribución especial del Presidente de la República, con el acuerdo del Consejo de Seguridad Nacional, declarar los estados de excepción constitucional (artículo 32.7 del texto constitucional), se contemplan cuatro regímenes de excepción: estado de asamblea, motivado por guerra externa; estado de sitio, por guerra interna o conmoción interior; el estado de emergencia, en casos graves de alteración del orden público o peligro para la seguridad nacional por causa interna o externa y estado de catástrofe por camalidad pública (artículo $39^{\circ}$, artículo reformado por el Artículo Único No 19 de la Ley de Reforma Constitucional No 18.825, de 17 de agosto de 1989). La suspensión de derechos es gradual según la causa que provoca el estado específico.

47 En la Constitución de Ecuador los estados excepcionales no se regulan en un título específico de la misma, sino dentro de las normas referentes a los poderes y deberes del Presidente, quien puede declarar la emergencia nacional y asumir poderes excepcionales en supuestos de inminente agresión externa, guerra internacional y de guerra interior o de catástrofe interna. Véase Hernán Salgado Pesantes, «El régimen de excepción y los Derechos Humanos en la actual Constitución de Ecuador", La Corte y el Sistema Interamericano de Derechos Humanos, op. cit. 
del artículo $121^{\circ}$. El mismo decreto presidencial de suspensión equivale a la convocatoria de la Asamblea a sesiones a fin de confirmar aquella medida (artículo 140.4) ${ }^{48}$.

\subsubsection{Otros poderes del Presidente}

Junto a estos dos grandes bloques de poderes que acabamos de estudiar, los presidentes latinoamericanos ostentan los que a continuación pasamos a relacionar brevemente.

\subsection{3.a Ejecución de las leyes y mantenimiento del orden}

Los presidentes latinoamericanos, antes de entrar a desempeñar sus cargos, juran o prometen guardar y hacer guardar la Constitución y las leyes, obligación que en numerosas ocasiones también se contemplan expresamente en los textos constitucionales como una de las obligacio-

48 Otros ejemplos de concesión de poderes extraordinarios a la figura del Presidente de la República en situación de estados excepcionales los encontramos en: artículos $23^{\circ}$ y 99.16 de la Constitución argentina (referidos al estado de sitio); artículos $111^{\circ}$ a $115^{\circ}$ de la Constitución de Bolivia (sobre el estado de sitio y la conservación del Orden Público, donde se prevé el control de los actos del Ejecutivo, posterior a la finalización del estado); artículos $84 . I X$ y $136^{\circ}$ a $139^{\circ}$ de la Constitución de Brasil (estado de defensa y estado de sitio donde se estiman suspendibles una serie de derechos); artículos $212^{\circ}$ a $215^{\circ}$ de la Constitución Política de Colombia (estado de guerra exterior, estado de conmoción interior y estado de emergencia, si bien, hemos de apuntar que, a diferencia de lo que ocurre en otros textos, el artículo 214.2 garantiza que "en los estados de excepción no podrá suspenderse los derechos ni las libertades fundamentales"); artículo 183 f) de la Constitución de la República de Guatemala (estado de emergencia grave o de calamidad pública, al que se hace alusión también en el artículo $139^{\circ}$, donde se remite a la Ley Constitucional de Orden Público y Estados de Excepción); artículo $29^{\circ}$ de la Constitución mexicana; artículo 150.9 de la Constitución de la República de Nicaragua; artículo $51^{\circ}$ de la Constitución de Panamá (estado de urgencia); artículo $288^{\circ}$ de la Constitución de Paraguay (donde se especifica escuetamente que los poderes excepcionales del Ejecutivo se reducen a «la detención de las personas indicadas de participar en algunos de esos hechos, su traslado de ellos de un punto a otro de la República, así como la prohibición o restricción de reuniones públicas y manifestaciones»); artículo $137^{\circ}$ de la Constitución del Perú (estado de emergencia y estado de sitio) y artículo 168.17 de la Constitución de la República Oriental del Uruguay (precepto que impone la obligación del Ejecutivo de rendir cuentas a la Asamblea sobre su actuación en el plazo de veinticuatro horas). 
nes que pesan sobre aquéllos ${ }^{49}$. Así pues, los presidentes latinoamericanos se nos presentan como defensores de la Constitución. Por lo demás, como jefes de la administración pública tienen el deber de ejecutar fielmente las leyes tal y como disponen los preceptos constitucionales ${ }^{50}$. Además, concretamente del deber de ejecución de las leyes deriva la titularidad presidencial de un poder reglamentario ${ }^{51}$.

\subsection{3.b Nombramiento y revocación de cargos públicos}

Como ya hemos señalado, el presidente es elegido individualmente; quiere esto decir que la elección del personal político y burocrático que compone el Ejecutivo, así como algunos miembros del Poder Judicial, serán competencia exclusiva del Presidente, que en numerosos casos deberá contar con la aprobación del Senado ${ }^{52}$. Ahora bien, hemos de

49 Compruébese en las Constituciones de Argentina, artículo $93^{\circ}$; Bolivia, artículo $92^{\circ}$; Brasil, artículo $78^{\circ}$; Colombia, artículos $188^{\circ}$ y $192^{\circ}$; México, artículo $87^{\circ}$; Nicaragua, artículo 150.1 y Panamá, artículo $176^{\circ}$. En Estados Unidos, Artículo II, Sección 1, parágrafo 7 .

50 Artículos $93^{\circ}$ de la Constitución de Argentina, 96.1 de la Constitución de Bolivia, 183.a) y b) de la Constitución de Guatemala, 78.a) y d) de la Constitución de Ecuador, 238.2 de la Constitución de Paraguay, 118.1 de la Constitución de Perú, 168.1 de la Constitución de Uruguay y $190^{\circ}$ primero de la Constitución de Venezuela, así como el Artículo II, Sección 3 in fine de la Constitución de Estados Unidos.

51 A diferencia de lo que ocurre en la Carta Magna estadounidense, donde la titularidad presidencial de un poder reglamentario se infiere de la denominada "take care clause", ubicada en el Artículo II, Sección 3, que dispone que el Presidente "cuidará de que las leyes se ejecute puntualmente», (véase el capítulo anterior), el poder reglamentario es explícitamente conferido al Presidente de la República en las Constituciones latinoamericanas: artículo 99.2 de la Constitución de Argentina; 96.1 de la de Bolivia; 189.11 de la de Colombia, 32.8 de la de Chile, que permite no sólo la emanación de reglamentos de ejecución, sino también de los denominados reglamentos independientes, 78.c) de la de Ecuador, 150.10 de la de Nicaragua, 118.8 de la de Perú y 190 Décimo de la de Venezuela.

52 En materia de nombramientos presidenciales podemos aludir a los siguientes artículos constitucionales: 99.7 y 99.19 de Argentina, 96.15 y 96.16 de Bolivia, 89. XV, 89.XVI y 89.XVII de Brasil, 189.1 y 189.13 de Colombia, 139.1 de Costa Rica, 32.9, 32.12 y 32.14 de Chile, 78.e) de Ecuador, 83.s) de Guatemala, 89.II de México, 150.6 de Nicaragua, 178.1 de Panamá, 238.6 de Paraguay, 168.13 de Uruguay y 190 Segundo y Décimoséptimo de Venezuela. La exigencia del acuerdo del Senado (y en algunos supuestos de la Cámara de Diputados), y de las respectivas Comisiones 
puntualizar que, como ocurre en Estados Unidos, el consentimiento del Senado, requerido por los textos constitucionales, limita la capacidad de acción del Ejecutivo y puede llegar a bloquear la propuesta presidencial, pero, en ningún caso, el Presidente queda despojado de su poder exclusivo de formular propuestas sucesivas tendentes a obtener la efectividad de sus directrices políticas.

Por lo que al cese de los cargos públicos por parte del Presidente se refiere, ésta es una facultad que, a diferencia de la regulación constitucional estadounidense, expresamente se contempla en algunas Cartas latinoamericanas en relación con determinados $\operatorname{cargos}^{53}$. Independientemente de ello, no podemos dejar de tener en cuenta que otra forma de cese de cualquier cargo ejecutivo es la de la exigencia de la responsabilidad criminal por medio del procedimiento de impeachment.

\subsection{3.c Poderes administrativos}

Los poderes administrativos del Presidente no siempre son explícitamente enunciados en las Constituciones ${ }^{54}$, sino que, a semejanza de lo

Permanentes, en su caso, en relación con los nombramientos se contempla en el artículo 99.4 de la Constitución de Argentina, artículo 96.4 de la Constitución de Bolivia, artículo 89.XIV de la Constitución de Brasil, artículo 32.11 de la Constitución de Chile, artículos 89.III, 89. IV, 89. XVI y 89.XVIII de la Constitución de México, artículo 168.13 de la Constitución de Uruguay y artículo $190^{\circ}$ Décimosexto de la Constitución de Venezuela. En relación con Estados Unidos, Artículo II, Sección 2, parágrafos segundo y tercero.

53 Así, los artículos 139.1 de la Constitución de Costa Rica, 32.9 de la Constitución de Chile, 183.s) de la Constitución de Guatemala, 89.II de la Constitución de México, 150.6 de la Constitución de Nicaraguat, 178.1 de la Constitución de Panamá, 238.6 de la Constitución de Paraguay y $190^{\circ}$ Segundo de la Constitución de Venezuela. Especial mención merece el artículo 168.10 de la Constitución de Uruguay, que exige el acuerdo de la Cámara del Senado o, en su receso, el de la Comisión Permanente para la destitución de los empleados por ineptitud, omisión o delito.

54 Como excepciones pueden mencionarse los artículos 84.II y 84.VI de la Constitución de Brasil, que confieren al Presidente la dirección y organización de la Administración Federal Superior; el artículo 183.h) de la Constitución de Guatemala que expresamente reconoce al Presidente como el superior jerárquico de los funcionarios y empleados del Organismo Ejecutivo y el artículo 178.2 de la Constitución de Panamá, que otorga al Presidente la función de coordinación de la labor de la Administración y establecimientos públicos. 
que ocurre en Estados Unidos, derivan del deber de ejecución de las leyes y mantenimiento del orden y de la facultad de nombramiento y destitución de funcionarios que le competen. Dichos poderes se traducen en la suprema dirección y coordinación e inspección de la Administración ${ }^{55}$.

Como en Estados Unidos, el contrapeso a estos poderes administrativos puede residenciarse en la facultad que corresponde a la rama legislativa para nombrar comisiones investigadoras, recabar información y exhibición de documentos, así como también en el poder de aprobación de créditos, con base en el cual (concretamente, en la negativa de créditos), puede influir y obstaculizar la dirección política y gestión administrativa presidenciales ${ }^{56}$.

\subsection{3.d Politica Exterior}

Los poderes que, en materia de política exterior, ostenta el Presidente se pueden sistematizar de la siguiente forma:

a. Recepción y nombramiento de agentes diplomáticos

Las Constituciones asignan al Presidente la recepción de embajadores y agentes diplomáticos y su nombramiento con el consentimiento del Senado ${ }^{57}$.

55 Maurice Duverger, Instituciones Políticas y Derecho Constitucional, op. cit., pp. 314-315 y Manuel García Pelayo, Derecho Constitucional Comparado, Alianza Universidad Textos, Madrid, 1991 (1 ${ }^{\text {a }}$ edición, $2^{\text {a }}$ reimpresión), pp. 378-379.

56 Véase, Manuel García Pelayo, Derecho Constitucional Comparado, op. cit., p. 405 y Luis Sánchez Agesta, Curso de Derecho Constitucional Comparado, op. cit., p. 209.

57 Véase los artículos 99.7 y 99.11 de la Constitución de Argentina, 96.3 y 66.10 de la Constitución de Bolivia, 183.p) de la Constitución de Guatemala, 89.III de la Constitución de México, 238.7 de la Constitución de Paraguay, 168.12 y 168.15 de la Constitución de Uruguay, que sólo exige el acuerdo del Senado cuando se trate del nombramiento de Jefes de Misión y 190 Décimosexto de la Constitución de Venezuela. No exigen la aprobación senatorial el artículo 189.2 de la Constitución de Brasil y el artículo 32.10 de la Constitución de Chile. Por su parte, la Constitución de Perú, en su artículo 118.12 exige la previa aprobación del Consejo de Ministros y rendir cuentas al Congreso para el nombramiento de los Embajadores, no así en el caso de recepción de agentes diplomáticos (artículo 118.13). Respecto al texto estadounidense, consúltese el Artículo II, Sección 2, parágrafos primero y segundo. 
b. Conclusión de Acuerdos Internacionales

Dicha conclusión se llevará a cabo previo acuerdo de alguna de las Cámaras ${ }^{58}$. Esta intervención no tiene porqué ser un mero control, sino que las Cámaras pueden llegar a condicionar su consentimiento a la aceptación de las enmiendas que propongan ${ }^{59}$.

c. Dirección de la política exterior y las relaciones internacionales Además de la expresa atribución de esta facultad en los textos constitucionales ${ }^{60}$, la efectiva dirección de la política internacional por parte del Presidente deriva, como en el caso estadounidense, del hecho de que en la medida en que a quienes pueda corresponder la dirección de las relaciones internacionales -agentes diplomáticos y Departamento de Asuntos Exteriores- se encuentran subordinados al Presidente, cabe concluir que es éste quien efectivamente dirige la política internacional. Todo ello se ve confirmado en la práctica con el hecho de que las grandes decisiones en este ámbito han sido tomadas personalmente por el Presidente, quien incluso llega a conducir por sí mismo las negociaciones ${ }^{61}$.

58 Artículos 99.11 y 75.22 de la Constitución de Argentina, el 96.2 de la de Bolivia, 89.VIII y 49.I, que exige Resolución del Congreso Nacional en caso de tratados, acuerdos o actos internacionales que graven el patrimonio nacional, de la de Brasil, 189.2 de la de Colombia, 32.17 de la de Chile, 78.f) de la de Ecuador, 183.k) y 183.o) de la de Guatemala, 89.X de la de México, 150.8 de la de Nicaragua, 238.7 de la de Paraguay, 118.11 de la de Perú y 168.20 de la de Uruguay. En Estados Unidos el Artículo II, Sección 2, parágrafo segundo de la Constitución exige una mayoría de dos tercios del Senado para la ratificación de los tratados internacionales.

59 En Estados Unidos son ampliamente conocidos algunos casos en los que el Senado ha rechazado o modificado sustancialmente lo negociado por la Presidencia, como ocurrió con la admisión de Estados Unidos a la Sociedad de Naciones o con los Tratados de Desarme SALT con la antigua Unión Soviética, o los casos en los que es el Congreso el que debe ratificar un acuerdo internacional, como ocurrió en 1993 con el NAFTA - North American Free Trade Agreement- realizado con México y Canadá. Eduardo Vírgala Foruria, "La forma de gobierno semiparlamentaria...", op. cit., p. 124.

60 Artículo 96.3 de la Constitución de Bolivia, artículo 78.f) de la Constitución de Ecuador, artículo 183.o) de la Constitución de Guatemala, artículo 89.X de la Constitución de México, artículo 150.8 de la Constitución de Nicaragua, artículo 238.7 de la Constitución de Paraguay y artículo 118.11 de la Constitución de Perú.

61 Véase Manuel García Pelayo, Curso de Derecho Constitucional Comparado, op. cit., p. 382. 


\section{d. Representación de la unidad del Estado}

El Presidente, como Jefe del Estado, tiene encomendada la representación de la unidad del mismo, lo que se plasma en los actos unilaterales de rango internacional para los que no se exige el acuerdo del Senado ${ }^{62}$.

\subsection{3.e Competencias militares}

En asuntos militares se atribuye al presidente el mando de las Fuerzas Armadas, en virtud de los cuales posee un amplio abanico de poderes expresamente recogidos en los textos constitucionales ${ }^{63}$ :

- El nombramiento (y en algunos casos la remoción) de los altos mandos militares, propuesta de ascenso de los mismos y la concesión de grados, que requieren el acuerdo del Senado en numerosos supuestos.

- El poder de organizar a la fuerza pública, así como disponer de su empleo.

- La dirección política y estratégica de la guerra ${ }^{64}$.

62 Así viene expresamente previsto en los siguientes preceptos constitucionales: artículo $181^{\circ}$ de la Constitución de Colombia, artículo de la Constitución de Ecuador, artículo $182^{\circ}$ de la Constitución de Guatemala, artículo 150.2 de la Constitución de Nicaragua y artículo 118.2 de la Constitución de Perú.

63 Véase los artículos 99.12, 99.13, 99.14 y 99.15 de la Constitución de Argentina; 96.18, 96.19, 96.20, 96.21 y $97^{\circ}$ de la Constitución de Bolivia; 89. XIII, 89. XVIII, 89. XIX y 89.XX de la Constitución de Brasil; 189.3, 189.5, 189.6 y 189.19 de la Constitución de Colombia; 32.18, 32.19, 32.20 y 32.21 de la Constitución de Chile; 78.h), 78, i), 78.j), 78.k), 78.l) y 78.11) de la Constitución de Ecuador; 183.d) y 183.e) de la Constitución de Guatemala; 89.IV), 89.V), 89.VI), 89.VII) y 89.VIII) de la Constitución de México; $144^{\circ}$ de la Constitución de Nicaragua; 238.7 y 238.9 de la Constitución de Paraguay; 118.14, 118.15 y 118.16 de la Constitución de Perú; 168.12 , 168.15 y 168.20 de la Constitución de Uruguay y $190^{\circ}$ Tercero, $190^{\circ}$ Cuarto y $190^{\circ}$ Séprimo de la Constitución de Venezuela. En cuanto a la Constitución de Estados Unidos hay que estar a lo previsto por los Artículos II, Sección, parágrafo primero ab initio y Artículo I, Sección 8, parágrafos undécimo a décimosexto (por lo que a las competencias militares del Congreso se refiere).

64 «[... [a dirección de la guerra es aquélla en que mayor grado exige las cualidades que caracterizan al poder cuando se ejerce por unas solas manos», Hamilton, El Federalista. Los ochenta y cinco ensayos que Hamilton, Madison y Jay escribieron en 
- La declaración de guerra y firma de la paz, previa autorización de una de las cámaras legislativas.

\subsection{3.f El derecho de gracia}

En virtud del mismo el Presidente tiene la facultad de otorgar el perdón en relación con los delitos cometidos, quedando excluidos los supuestos de impeachment ${ }^{65}$. El indulto no es un acto de gracia o personal sino que forma parte del sistema constitucional ${ }^{66}$.

\subsection{Limitaciones}

La preeminencia del presidente a la que conduce la atribución de un mayor poder respecto de los otros poderes, trata de contrarrestarse en las constituciones latinoamericanas mediante una serie de prohibiciones y controles, que son los que pasamos a estudiar seguidamente ${ }^{67}$.

apoyo de la Constitución Norteamericana, México, Fondo de Cultura Económica, 1982 ( $1^{\text {a }}$ edición, $3^{\text {a }}$ reimpresión), LXXIV, p. 316.

65 Este derecho viene previsto en las Constituciones de Bolivia, artículo 96.13; Brasil, artículo 89.XII; Chile, artículo 32.16; México, artículo 89.XIV; Paraguay, artículo 238.10; Perú, artículo 118.21 y Venezuela, artículo $190^{\circ}$ Vigésimoprimero. La misma facultad concede el Artículo II, Sección 2, parágrafo primero al Presidente de los Estados Unidos.

66 La jurisprudencia norteamericana entiende el derecho de gracia no como un acto de gracia sino de orden público y, en este sentido, ha establecido que «un indulto en nuestros días no es un acto privado de gracia del individuo que resulta tener poder para ello; es una parte del sistema constitucional. Se concede en virtud de que la autoridad suprema ha resuelto que el bien público estará mejor servido si el castigo es menor de lo que fijó la sentenciam. Sentencia Biddle vs. Perovich, citada en Manuel García Pelayo, Derecho Constitucional Comparado, op. cit., p. 387. La concepción del indulto como generosa prerrogativa en manos del Presidente puede observarse en Hamilton, El Federalista, LXXIV, op. cit., pp. 316-318.

67 Estas prohibiciones se orientan a evitar los fenómenos de "continuismo", golpes de Estado y caudillismo. En su trabajo, Viviana Krsticevic pretende constatar, sobre la base del análisis de los sistemas de control y límites a las facultades presidenciales, cómo "[...] el Ejecutivo predominante no quiebra en el plano normativo el objetivo de no abuso del poder/control establecido en la teoría de separación de poderes". Viviana Krsticevic, "Presidencialismo en América Latina", op. cit., pp. 134 y $141-142$. 


\subsubsection{Duración limitada del cargo y fijación del mandato}

Ya el constitucionalismo liberal decimonónico iberoamericano, en un intento de querer diferenciar el presidencialismo de la autocracia, impone la limitación temporal en el ejercicio del cargo ${ }^{68}$. En los actuales regímenes presidenciales la duración del mandato presidencial oscila entre los cuatro y seis años, con la excepción de Chile, cuyo texto prevé el mandato más amplio (ocho años, según dispone el artículo $25^{\circ}$ de la Constitución $)^{69}$.

Aunque la fijación del mandato presidencial podría reputarse como una circunstancia que dota de mayor estabilidad al Ejecutivo, Serrafero constata la existencia de una serie de paradojas que en la práctica ponen en tela de juicio esta presunción: los problemas de sucesión en el cargo que generan la muerte o incapacidad del Presidente, el juego de «suma cero", puesto de manifiesto por Linz, donde el ganador de las elecciones se lo lleva todo, el riesgo de utilizar prácticas autoritarias que invitan a un presidencialismo en clave de "régimen mayoritario" y resta todo posible espacio a la oposición (los partidos de la oposición no encuentran incentivos para cooperar con el Presidente: si la coalición tiene éxito, el mérito se lo lleva el Presidente, si se produce el fracaso se achaca a la coalición, en definitiva, es más ventajoso criticar al Presidente). De hecho, pensamos, todo ello aumenta la polarización política en un marco, el de la transición a la democracia, en el que la cooperación, la negociación y la confianza se reputan esenciales en pro de la estabilidad. Además, la limitación temporal del mandato genera en el titular del cargo un sentimiento de «irresponsabilidad política» de

68 Así, Serrafero alude a los ejemplos de Chile, Argentina y Venezuela. Mario D. Serrafero, "Presidencialismo y Reforma Política en América Latina», op. cit. p. 216.

69 Concretamente, el mandato del Presidente de la República se prolonga duran-

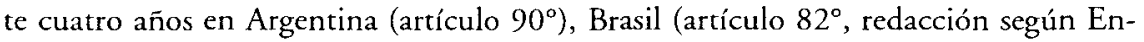
mienda Constitucional de Revisao 05/94), Colombia (artículo 190%), Costa Rica (artículo $134^{\circ}$ ); durante cinco años en Bolivia (artículo $87^{\circ}$, redactado según ley de Reforma a la Constitución Política del Estado No 1585, de 12 de agosto de 1994), Guatemala (artículo $184^{\circ}$ ), Ecuador (artículo $73^{\circ}$ ), Nicaragua (artículo 148 ), Panamá (artículo $172^{\circ}$ ), Paraguay (artículo $229^{\circ}$ ), Perú (artículo $112^{\circ}$ ), Uruguay (artículo $152^{\circ}$ ) y Venezuela (artículo $135^{\circ}$ ); y se extiende hasta los seis años en México (artículo $83^{\circ}$ ). 
su gestión, ya que no se verá sometido a nueva prueba electoral ${ }^{70}$. Sea como fuere, lo que sí parece ser cierto es que dicha estabilidad es indispensable para que el Poder Ejecutivo pueda ser efectivo ${ }^{71}$.

Por último, en relación con la rigidez en las fechas de las elecciones presidenciales hemos de apuntar, como consecuencia negativa, que las constituciones latinoamericanas, no incluyen mecanismos mediante los cuales se pueda reemplazar a un presidente políticamente desacreditado, sin esperar a la finalización del mandato. En otras palabras, ante un presidente impopular o que ha perdido gran parte de su apoyo parlamentario, no cabe el mecanismo parlamentario del voto de censura. Ello provoca una menor flexibilidad a la hora de abordar una situación de crisis. En muchos casos, el golpe de estado parece ser el único medio de librarse de un presidente incompetente o impopular. Por contraste, en un sistema parlamentario, el jefe del gobierno es elegido por el Legislativo y depende del mantenimiento de su confianza para continuar en el poder, así que el período de tiempo del mandato de la cabeza del Ejecutivo es alterable ${ }^{72}$.

70 Mario D. Serrafero, "Presidencialismo y Reforma Política en América Latina», op. cit., pp. 226-228. En relación a las reducidas opciones de actuación de que dispone la oposición, Gargarella sostiene que son las siguientes: complacencia, trasvasamiento (erosión desde dentro de la estructura de poder), oportunismo (dar un "apoyo crítico" al oficialismo), obstruccionismo y necesariedad (en este caso, el partido opositor concentra en sí el suficiente poder como para que el oficialismo encuentre indispensable una concertación entre ambos). Roberto Gargarella, "El Presidencialismo como sistema contramayoritario...", op. cit., pp. 92 a 94.

71 Sin embargo, Suárez, en materia de estabilidad, medida como duración efectiva del personal en sus cargos, constata en su estudio que la duración media de los Jefes de Estado es excesivamente breve en esta región; que la permanencia promedio del Presidente latinoamericano también es excesivamente breve en términos comparados; que en América Latina una gran proporción de los líderes han permanecido en sus cargos por períodos muy breves de tiempo y que la inestabilidad que parece afectar a la Jefatura de Estado se hace extensible a la elite ministerial. En cuanto a la certeza de la duración del cargo, distingue entre Poderes Ejecutivos «regulares», cuando el nombramiento del Presidente se ha hecho con base en normas fijadas con anterioridad a dicho nombramiento y de aplicación general, y transferencias «irregulares", cuando dichos reglamentos no existen, apuntando a la existencia de una mayor proporción de sucesiones irregulares que en el resto de las regiones del mundo. Véase Waldino Suárez, «El Poder Ejecutivo en América Latina...», op. cit., pp. 115 a 123.

72 En Chile, en 1973, los oponentes al Gobierno de la Unidad Popular temían que al permitir a Allende que completara sus seis años de mandato (1970-1976), se 


\subsubsection{Prohibición de reelección inmediata del Presidente}

Con la regla constitucional de prohibición de reelección de quien fuera presidente o vicepresidente, o en el período posterior la elección de quienes tuviesen una relación de parentesco con aquéllos o hubiesen formado parte del Ejecutivo, se pretende impedir que los presidentes iberoamericanos accionen su propia reelección y se perpetúen en el poder, lo que comportaría la transformación de un régimen democrático mediante la reiterada renovación del mandato presidencial $^{73}$.

Algunos juristas han sostenido que el principio de no-reelección es antidemocrático ya que limita la libertad del pueblo para reelegir a la persona que en su sentir puede seguir ocupando el cargo por sus características e incluso provoca una tendencia a la aceleración en el diseño y aplicación del programa político por parte del presidente, sin embargo, otros se decantan a su favor y señalan la función de fortalecimiento del sistema democrático que desempeña ${ }^{74}$.

abriera la puerta al socialismo autoritario. Allende había perdido el apoyo de la mayoría del Legislativo y en un sistema parlamentario hubieran votado para sustituirle en el cargo, sin embargo, en un sistema presidencial no había medio de reemplazarle excepto mediante un golpe. Scott Mainwaring, "Presidencialismo, multipartidismo y democracia...", op. cit., pp. 124-125.

73 Viviana Krsticevic, "Presidencialismo en América Latina", op. cit., p. 142; Humberto Nogueira Alcalá, "I Regimi Presidenciali dell'America Latina», op. cit., pp. 504-505 y Waldino Suárez, «El Poder Ejecutivo en América Latina...», op. cit., p. 129. Este último, sin embargo, constata en su trabajo cómo no está tan clara la cláusula de la no reelección como instrumento para el logro del mencionado objetivo. Ello se debe a tres tipos de razones. En primer lugar, el impacto que este tipo de limitaciones tiene sobre la estabilidad presidencial en América Latina. En segundo lugar, tampoco son demasiado obvias las bondades de una regla que obliga a los Presidentes a sentir, independientemente de carácter de su gestión, que no podrán, o por lo menos no inmediatamente, volver a servir a su país aun si su gobierno ha sido exitoso a los ojos de sus conciudadanos. En tercer lugar, la reelección no parece haber logrado su objetivo fundamental: evitar que líderes personalistas conserven una influencia decisiva sobre la política de sus respectivos países durante largos períodos de tiempo (así, A. Arias en Panamá, Velasco Ibarra en Ecuador, Paz Estensoro en Bolivia, Figueroa en Costa Rica y J. Perón en Argentina).

74 Tal es el caso de Carpizo en relación con sistema mexicano. Véase Jorge Carpizo y Jorge Madrazo, "El Sistema constitucional mexicano", en D. García Belaunde, F. Fernández Segado y R. Hernández Valle, Los sistemas constitucionales iberoamericanos, Editorial Dykinson, Madrid, 1992, p. 590. 
Como acabamos de apuntar en el comienzo del subepígrafe las limitaciones a la elegibilidad también pueden estar fundadas en una relación de parentesco (dentro del cuarto grado de consanguinidad y segundo de afinidad) o la pertenencia a la plantilla del Gobierno ${ }^{75}$.

\subsubsection{Exclusión de determinados grupos}

Además de las limitaciones a la elección que acabamos de estudiar, gran parte de los textos constitucionales de la región excluyen miembros de algunos determinados grupos, parece ser que con el fin de evitar la tiranía de facciones o grupos privados, la representación autointeresada, o de no distorsionar la voluntad de la mayoría gobernando para favorecer intereses minoritarios ${ }^{76}$.

\subsubsection{Las Fuerzas Armadas}

Históricamente, desde la emancipación de las colonias iberoamericanas, el ejército se ha presentado como un elemento decisivo de poder

75 La prohibición por razón de parentesco la encontramos en Bolivia, artículo 89.2; Colombia, artículo $197^{\circ}$; Costa Rica, artículo 132.2; Guatemala, artículos 164.c) y 186 c); Ecuador, artículo 79.3; Nicaragua, artículo $147^{\circ}$, párrafo tercero; Panamá, artículo $187^{\circ}$; Paraguay, artículo 235.9) y Venezuela, artículo $184^{\circ}$ (en este caso de Venezuela la prohibición de circunscribe al tercer grado de consanguinidad y el segundo de afinidad).La prohibición que hace referencia a la pertenencia del Gobierno saliente puede observarse en Bolivia, artículo 89.1; Colombia, artículo 197\% Rica, artículo 132. 4; Guatemala, artículos 164.a) y 186.b); Ecuador, artículo 79.1), 4) y 5); México, artículo 82.VI); Nicaragua, artículo $147^{\circ}$, párrafo tercero; Paraguay, artículo 235.1) y Venezuela, artículo $184^{\circ}$, párrafo segundo.

76 Viviana Krsticevic, "Presidencialismo en América Latina", op. cit., p. 144. A título de ejemplo, podemos hacer alusión a la prohibición de ser electo Presidente a quien pertenezca al clero o sea ministro de cualquier religión en las Cartas de Bolivia, artículo 89.3; Guatemala, artículo 186.f); México, artículo 82.IV); Nicaragua, artículo $147^{\circ}$, párrafo tercero y Paraguay, artículo $235^{\circ}$. En general, sobre materia de causas de inegibilidad que conciernen al Presidente consúltese las Constituciones de: Bolivia, artículo $89^{\circ}$; Colombia, artículo $197^{\circ}$; Costa Rica, artículo $132^{\circ}$; Guatemala, artículo $186^{\circ}$; Ecuador, artículo $79^{\circ}$; México, artículo $82^{\circ}$; Nicaragua, artículo $147^{\circ}$, párrafo III; Panamá, artículos $175^{\circ}$ y $187^{\circ}$ y Paraguay, artículos $235^{\circ}$ y $236^{\circ}$. 
que ha de ser tenido en cuenta a la hora de gobernar ${ }^{77}$. Mientras que en los textos constitucionales se hace hincapié en el hecho de que la Fuerza Armada tiene un carácter obediente y que sus principales responsabilidades son la defensa del territorio nacional, el respaldo a la Constitución y a las leyes y el mantenimiento del orden interno, la experiencia nos demuestra que la historia de Iberoamérica está plagada de pronunciamientos, intervenciones militares y golpes de Estado.

Con la finalidad de no permitir los golpes de Estado, revoluciones e injerencias en la vida política, en las constituciones latinoamericanas se prevén diversas disposiciones al efecto ${ }^{78}$. De entre ellas hemos de comenzar por resaltar la más radical, que no es otra que el artículo $12^{\circ}$ de la

77 Duverger explica esta atracción del Ejército por la política y el ejercicio del poder aludiendo a las siguientes causas: la importancia de los efectivos humanos y militares de que dispone; la formación de carácter técnico que recibe el militar profesional en centros especializados, dicha formación, que abarca los grandes temas nacionales (económicos, sociales y políícos) aproxima a los nuevos oficiales, en conocimientos y mentalidad, a las actuales tendencias tecnocráticas; y por último su sentido patriótico y su experiencia en la adopción de decisiones. Maurice Duverger, Instituciones Políticas y Derecho Constitucional, op. cit., p. 625. Entre los estudios dedicados a la intervención de las Fuerzas Armadas en la política, podemos mencionar la obra Posición Constitucional de la Fuerzas Armadas en Iberoamérica y en España, Tecnos-Universidad Hispanoamericana Santa María de la Rábida. Universidad de Sevilla, Madrid-Sevilla, 1992. También, Ismael Crespo Martínez y Fernando Filgueira, "La intervención de las Fuerzas Armadas en la política latinoamericana", Revista de Estudios Políticos, No 80, Abril-Junio 1993, pp. 297-31 1; Mabel Olivieri, "Orígenes y evolución de la presencia militar en América Latina», Revista de Estudios Políticos, $N^{\circ} 42$, 1984, pp. 163-188 y Juan Rial, "Las Fuerzas Armadas de América del Sur y su relación con el Estado en el nuevo contexto democrático, en un mundo en cambio constantem, Revista de Estudios Políticos, $\mathrm{N}^{\circ} 74$, Octubre-Diciembre 1991, pp. 55-84. Véase también, Helgio Trinade, «El Tema del Fascismo en América Latina", Revista de Estudios Políticos, $\mathrm{N}^{\circ} 30,1982$, pp. 111-141, donde mantiene que a partir del golpe de Estado militar de 1964 en Brasil se inaugura una nueva fase en la historia de las intervenciones militares en América Latina que hacen atribuir el concepto de fascismo a los nuevos regímenes instaurados. Por su parte Cardoso, a la hora de tipificar los regímenes militares en América Latina, se pronuncia a favor de la explicación planteada por el modelo burocrático-autoritario de O'donnell, véase Fernando Henrique Cardoso, «Sobre la caracterización de los regímenes autoritarios en América Latina», en David Collier (Ed.), El nuevo autoritarismo en América Latina, México, FCE, 1986.

78 Viviana Krsticevic, "Presidencialismo en América Latina», op. cit., p. 143. 
Constitución de Costa Rica, que proscribe el ejército como institución permanente y establece que de existir una fuerza militar habrá de subordinarse al poder civil. Otras constituciones no llegan a este extremo, pero aluden a la subordinación de las Fuerzas Armadas a las autoridades civiles $^{79}$. A la misma finalidad responden aquellas normas que prohiben la elección como presidente o miembro del Poder Ejecutivo a la persona que pertenezca a las Fuerzas Armadas o de seguridad, o que haya dejado de pertenecer en los seis meses anteriores a la elección ${ }^{80}$.

\subsubsection{El Impeachment}

Como sabemos, una de las características que definen al constitucionalismo democrático consiste en el principio de responsabilidad (civil, penal o política) de los actos llevados a cabo en el ejercicio de los cargos públicos.

El impeachment como verdadero "juicio parlamentario" no existe en todos los países de Iberoamérica, sino que lo encontramos en Brasil, Ecuador, Panamá y Uruguay. Son las Cámaras del Congreso las que acusan y juzgan a los funcionarios imputados, y si los encuentran culpables, pueden destituirlos de sus cargos y remitirlos luego a la Justicia a los efectos del correspondiente juicio por presuntos delitos. En Costa Rica, Chile y Guatemala, la Cámara o el Senado se limitan a declarar si hay lugar o no a la formación de proceso contra el presidente, y en caso positivo se lo envía a la justicia ordinaria ${ }^{81}$. En Venezuela, el Se-

79 Así, la Carta Magna mexicana (artículo $136^{\circ}$ ) prevé que dicho texto no perderá su fuerza y vigor aun cuando por alguna rebelión se interrumpa su eficacia, y la Constitución venezolana afirma en su artículo $119^{\circ}$ que toda autoridad usurpada es ineficaz y sus actos nulos y que las Fuerzas Armadas deben respeto a la Constitución y a las leyes, cuyo acatamiento estará siempre por encima de cualquier obligación (artículo $132^{\circ}$ ).

80 Así, Bolivia, artículo $89^{\circ}$; Ecuador, artículos 58.f) y 79.6; Guatemala, artículos 164.f) y 186 a) y e) y México, artículo $82 . V$. Especialmente ilustrativo de la finalidad perseguida se nos antoja el tenor del artículo 186.a) de la Constitución de Guatemala.

81 Sostiene Serrafero que el envío del Presidente a la justicia ordinaria es una medida ineficaz, dado que el Ejecutivo interviene en la designación de los jueces, dificultad ésta que hay que sumar al requerimiento de determinadas mayorías en el Congreso, muy difíciles de obtener. Mario D. Serrafero, «Presidencialismo y Reforma Política en América Latina», op. cit., p. 224. 
nado se limita sólo a autorizar el juicio, después de que la Corte Suprema haya declarado que hay mérito para ello (artículo $150^{\circ}$, párrafo octavo $^{82}$ ).

En definitiva, en América Latina no existe un diseño homogéneo de la institución del juicio político, como tampoco lo existe con relación a las causas que lo propician. De cualquier forma, se siga el procedimiento que se siga, es común a todas las regulaciones el elevado quórum que se exige para activar este procedimiento de exigencia de responsabilidad. A ello hemos de añadir la constatación de que no se puede aplicar por razones meramente políticas y la lentitud del proceso, todo lo cual hace que se nos presente como una institución poco efectiva a la hora de hacer frente a las situaciones conflictivas entre poderes que aquejan a la región.

\section{Las relaciones del Poder Ejecutivo y el Poder Legislativo}

Aun cuando puede afirmarse la vigencia en el sistema presidencial de la separación rígida de poderes, frente a la interrelación entre los mismos que se da en el sistema parlamentario, seguidamente hemos de advertir que dicha separación no es tan rígida y que en algunos ámbitos, tal y como ya hemos podido estudiar y como vamos a comprobar en este epígrafe, se producen superposiciones y $\operatorname{conflictos}^{83}$. Precisamente en

82 Un análisis de la destitución de Carlos A. Pérez en 1993 a raíz de la activación del proceso de impeachment, en Mario D. Serrafero, "El “impeachment" en América Latina: Argentina, Brasil y Venezuela», Revista de Estudios Políticos, N² 92, 1996, pp. 147 a 152 .

83 Algo semejante ocurre en relación con Estados Unidos, donde un estudio de su sistema político confirma la vigencia del principio de separación de poderes de forma rígida, en la medida en que se atribuye estrictamente a un órgano la legislación y a otro órgano la ejecución de la misma. Es decir, la separación orgánica entre el Poder Ejecutivo y el Poder Legislativo y la organización de los partidos políticos, permite afirmar que en los Estados Unidos el principio de separación de poderes ha conseguido una implantación institucional bastante más amplia que en los sistemas parlamentarios europeos. Ahora bien, pese a que la Constitución prevé una relación entre Ejecutivo y Legislativo reducida a elementos mínimos, dada esa vigencia de la estricta separación de poderes, la práctica nos ofrece todo un abanico de medios de control que hacen responsable a la acción del Presidente. Tampoco podemos dejar de 
este epígrafe vamos a describir, de forma muy general, la estructura y poderes de cada uno de los poderes, así como la relación entre ambos, a fin de subrayar los aspectos más sobresalientes de la misma.

En las constituciones latinoamericanas el Poder Ejecutivo está formado por un presidente (investido de amplios poderes, como ya hemos estudiado), un vicepresidente y sus ministros, a quienes el presidente nombra y remueve libremente ${ }^{84}$.

Los actos del presidente para tener validez necesitan ser refrendados por sus ministros ${ }^{85}$. Y en algunos casos se exige la actuación conjunta

tener presente que la propia Constitución prevé una cooperación en la función legislativa del Presidente, que puede recomendar al Congreso la adopción de las medidas que estime necesarias y puede oponer su veto a la legislación que considere inoportuna. Por lo demás, los reglamentos y legislación delegada que emana el Ejecutivo constituyen, no una cooperación, sino una forma de ejercicio propiamente dicho, de la citada función legislativa. Así pues, si se puede hablar de rigidez en la separación, dada la ausencia de mecanismos parlamentarios (como la confianza del Legislativo o la ausencia del poder de disolución del Ejecutivo), dicha rigidez no es absoluta, en la medida en que en la esfera del ejercicio de las funciones la nota dominante es el juego de los recíprocos controles y sistema de equilibrio. Así, tenemos que el Presidente de los Estados Unidos está limitado por la duración del mandato presidencial o por el control que el Congreso ejerce sobre sus propuestas legislativas (el Congreso puede discutir y enmendar las propuestas legislativas del Presidente y exige con frecuencia una información periódica de los poderes extraordinarios que delega).

84 Argentina, artículo 99.7; Bolivia, artículo 99 ; Brasil, artículo 84.I; Colombia, artículo 189.1; Costa Rica, artículo 139.1; Chile, artículo 32.9; Guatemala, artículo 183.s); Ecuador, artículos 78.e) y $85^{\circ}$; Nicaragua, artículo 150.6; Panamá, artículo 178.1; Paraguay, artículo 238.6 y Venezuela, artículo $190^{\circ}$ segundo). Como excepciones a esta regla general hemos de hacer mención a los casos de México (artículos 76.II y 89.III), donde se exige el acuerdo del Senado; Perú, donde el nombramiento por parte del Presidente de la República se lleva a cabo previa propuesta del Presidente del Consejo de Ministros (artículo $122^{\circ}$ ) y Uruguay (artículo $174^{\circ}$ ), donde se prevé que el Presidente procederá a nombrar a los Ministros que cuenten con apoyo parlamentario.

85 Así se prevé en los textos constitucionales de Argentina, artículo $100^{\circ}$, párrafo primero, que exige el refrendo del Jefe del Gabinete y los demás Ministros secretarios; Bolivia, artículo $102^{\circ}$; Brasil, artículo 87.I; Costa Rica, artículo $146^{\circ}$; Chile, artículo $35^{\circ}$, que exige el refrendo de los reglamentos y Decretos presidenciales; Guatemala, artículo 193.c; México, artículo $92^{\circ}$; Nicaragua, artículo $151^{\circ}$, párrafo segundo, donde se exceptúa de la exigencia de refrendo los actos de nombramiento y remoción de los Ministros y Viceministros; Panamá, artículo $181^{\circ}$, si bien quedan a salvo de la necesidad de refrendo los actos que el Presidente puede realizar por sí sólo; Perú, 
de todos los miembros del ejecutivo para la adopción de determinadas medidas ${ }^{86}$

En el Ejecutivo latinoamericano los ministros no han de pertenecer al Parlamento, de hecho, en la mayoría de las Constituciones se prohibe el ejercicio simultáneo de ambas funciones (representativa y ejecutiva). Junto a ellos, el Presidente es el jefe del Estado, del gobierno, de la administración y las Fuerzas Armadas, dirige las relaciones exteriores $\mathrm{y}$ tiene conferidos amplios poderes en el plano legislativo (la facultad de presentar proyectos de ley, la obligación de presentar el proyecto de Ley de Presupuesto, etc.) y en relación con los estados de excepción.

El Poder Legislativo es por regla general bicameral ${ }^{87}$ y de elección directa. Durante sus recesos una Comisión Permanente es la que continúa en funcionamiento y ejerce las atribuciones legislativas.

En cuanto a las relaciones entre ambos poderes ya hemos analizado cómo el presidente tiene conferidas una serie de atribuciones en el ámbito legislativo: promulga o veta las leyes que el Poder Legislativo emana y las publica y posee la iniciativa legislativa (en algunas ocasiones incluso de forma exclusiva) y la habilitación ${ }^{88}$; además, posee facul-

artículo $120^{\circ}$; Paraguay, artículo 238.5, que exige el refrendo de los Decretos del Presidente y Venezuela, artículo $190^{\circ}$ in fine, donde se exceptúan del refrendo obligatorio los actos de nombramiento y remoción de los Ministros y de ejercicio de la suprema autoridad jerárquica de las Fuerzas Armadas).

86 Sirva como ilustración de esta afirmación el Artículo $147^{\circ}$ de la Constitución costarricense.

87 Así, Argentina, artículo $44^{\circ}$; Bolivia, artículo $46^{\circ}$; Brasil, artículo $44^{\circ}$; Colombia, artículo $114^{\circ}$; Chile, artículo $42^{\circ}$; México, artículo $50^{\circ}$; Paraguay, artículo $182^{\circ}$; Uruguay, artículos $83^{\circ}$ y $84^{\circ}$ y Venezuela, artículo $138^{\circ}$. Como excepción a esta regla general, prevén un Parlamento unicameral, Costa Rica, artículo $105^{\circ}$; Guatemala, artículo $157^{\circ}$; Ecuador, artículo $56^{\circ}$; Nicaragua, artículo $132^{\circ}$; Panamá, artículo $140^{\circ}$ y Perú, artículo $90^{\circ}$.

$88 \mathrm{Al}$ respecto, consúltese los siguientes preceptos constitucionales: Argentina, artículos $77^{\circ}, 78^{\circ}, 80^{\circ}, 83^{\circ}$ y 99.3 ; Bolivia, artículos $71^{\circ}, 74^{\circ}, 76^{\circ}, 79^{\circ}, 96.7$ y $147^{\circ}$; Brasil, artículos $61^{\circ}, 62^{\circ}, 63.1,66^{\circ}, 67^{\circ}, 84 . I I I, 84 . I V, 84 . V$, y 84 XXVI; Colombia, artículos $150.10,154^{\circ}, 157.4,165^{\circ}, 166^{\circ}, 167^{\circ}, 168^{\circ}, 189.9,189.10$ y 200.1; Costa Rica, artículos, $123^{\circ}$ a $128^{\circ}, 140.3,140.5$ y 140.15 ; Chile, artículos, $32.1,37^{\circ}, 62^{\circ}$, $65^{\circ}, 67^{\circ}$ y $69^{\circ}$ a $72^{\circ}$; Guatemala, artículos, $174^{\circ}, 177^{\circ}$ a $\left.\left.179^{\circ}, 183 . \mathrm{c}\right), 183 . \mathrm{g}\right), 183 . \mathrm{h}$ ) y 183.j); Ecuador, artículos, $65^{\circ}, 68^{\circ}$ a $70^{\circ}$ y 78.b); México, artículos, 71.I, 72.A), B), C) y J), 74.4 y 89.I); Nicaragua, artículos $140.2,141^{\circ}$ a $143^{\circ}, 150.3$ y 150.5 ; Panamá, artículos, $153.16,160^{\circ}$ a $163^{\circ}, 165^{\circ}, 178.6$ y 179.7; Perú, artículos $78^{\circ}$, $104^{\circ}, 107^{\circ}$ y $108^{\circ}$; Paraguay, artículos, $203^{\circ}$ a $210^{\circ}, 213^{\circ}, 216^{\circ}, 238.3,238.12$ y 
tades para convocar al Parlamento a sesiones extraordinarias y ordinarias, así como en relación con la apertura y prórroga de sesiones ${ }^{89}$. A ello hay que unir las disposiciones constitucionales que permiten participar a los ministros en las discusiones del Parlamento con voz pero $\sin$ voto $^{90}$.

Por su parte, el Legislativo controla al Ejecutivo mediante la petición de informes, interpelaciones, comisiones de investigación e impeachment $t^{11}$. Además, en materia de control del Legislativo sobre el Ejecutivo, no podemos dejar de tener en cuenta la adopción, por parte de algunas regulaciones constitucionales, del mecanismo, genuinamente parlamentario, del voto de censura de los ministros ${ }^{22}$.

238.14; Uruguay, artículos $104^{\circ}, 133^{\circ}, 136^{\circ}, 137^{\circ}$ a $141^{\circ}, 145^{\circ}, 168.4,168.6 \mathrm{y}$ 168.7; Venezuela, artículos, $165^{\circ}, 167^{\circ}, 170^{\circ}, 172^{\circ}, 173^{\circ}, 175^{\circ}, 190^{\circ}$ Octavo y $228^{\circ}$.

89 Así, los siguientes preceptos constitucionales: Argentina, 99.8 y 99.9; Bolivia, $46^{\circ}$ y $96.5^{\circ}$ y $17 \circ$; Brasil, $57^{\circ}$ parágrafo $6^{\circ}$ II y 84 .XI; Colombia, $138^{\circ}, 139^{\circ}, 189.8$ y 200.2; Costa Rica, $118^{\circ}$ y 140.14 ; Chile, 32.2 y $52^{\circ}$; Guatemala, $158^{\circ}$ y 183.l; Ecuador, $64^{\circ}$; México, $66^{\circ}$ in fine, $69^{\circ}$ y 89.XI; Nicaragua, 150.7; Panamá, $143^{\circ} \mathrm{y}$ 178.4; Perú, 118.6; Paraguay, $184^{\circ}$ y 238.11 ; Uruguay, $104^{\circ}$ y 168.8 y Venezuela, 190 Noveno.

90 Confírmese con la consulta a los siguientes artículos constitucionales: Argentina, $106^{\circ}$; Bolivia, $103^{\circ}$; Costa Rica, $145^{\circ}$; Chile, $37^{\circ}$; Guatemala $168^{\circ}$ y $194 . h$ ); México, $93^{\circ}$ párrafo segundo; Perú, $129^{\circ}$; Uruguay, $180^{\circ}$ y Venezuela, $170^{\circ}$ y $199^{\circ}$.

91 Así lo prevén las Constituciones de: Argentina, artículos $59^{\circ}, 71^{\circ}$ y $101^{\circ}$; Bolivia, artículos $68.12,70^{\circ}, 83^{\circ}$ y $127.6^{a}$; Brasil, artículo $50^{\circ}$ (redactado según Enmenda Constitucional de Revisao 02/94), 51.I, 52.I, $85^{\circ}$ y $86^{\circ}$; Colombia, artículos $135^{\circ}, 137^{\circ}$ y $199^{\circ}$; Costa Rica, artículos $121.9,121.24$ y $148^{\circ}$ a $151^{\circ}$; Chile, artículos 48.1, 48.2.a), 48.2.b) y 49.1; Guatemala, artículos 165.h), 165.j), $166^{\circ}, 167^{\circ}$ y $199^{\circ}$; Ecuador, artículos 59.e), 59.f) y $87^{\circ}$; México, artículos $74 . \mathrm{V}, 93^{\circ}, 108^{\circ}$ párrafo segundo, 109.I y $110^{\circ}$ y ss; Nicaragua, artículos 138.4 y $151^{\circ}$ in fine; Panamá, artículos 154.1 y $155^{\circ}$; Paraguay, artículos $192^{\circ}, 193^{\circ}, 195^{\circ}$ y $225^{\circ}$; Perú, artículos $96^{\circ}$, $97^{\circ}, 99^{\circ}, 100^{\circ}$ y $131^{\circ}$; Uruguay, artículos $85.19,93^{\circ}, 102^{\circ}, 103^{\circ}, 118^{\circ}$ a $120^{\circ}, 147^{\circ}$ y $172^{\circ}$ y Venezuela, artículos $150^{\circ}$ Octavo, $160^{\circ}, 161^{\circ}$ y $198^{\circ}$.

92 Así, el artículo $101^{\circ}$ de la Constitución de Argentina, que permite la moción de censura del Jefe del Gabinete de Ministros, el artículo $135^{\circ}$ de la Constitución de Colombia, el 121.4 de la de Costa Rica, el $87^{\circ}$ de la de Ecuador, el $166^{\circ}$ y $167^{\circ}$ de la de Guatemala, el $194^{\circ}$ de la de Paraguay, el $132^{\circ}$ de la de Perú, el $147^{\circ}$ y $148^{\circ}$ de la de Uruguay y el $153^{\circ}$ de la de Venezuela. Especial mención merece el caso de la Constitución de Uruguay, donde en la regulación de la interrelación entre Poder Ejecutivo y Legislativo, junto a la moción de censura se contempla el poder de disolución de las Cámaras por el Presidente de la República, en el caso de que sean censurados uno o varios ministros por menos de tres quintos de los componentes de la Asamblea General. 
Para finalizar, no queremos dejar de apuntar que una de las cuestiones que en los últimos años constituye el objeto del debate académico y politico en Iberoamérica es el contraste de los resultados de eficacia y estabilidad obtenidos por las democracias parlamentarias de Europa occidental frente a los obtenidos por el presidencialismo en Latinoamérica93.

En el plano académico numerosas voces apuntan a la necesidad de reconversión del régimen democrático a través de formas parlamentarias o semiparlamentarias como única vía de consolidación de las democracias.

Concretamente, en países como Uruguay y Chile se ha sostenido la necesidad de instaurar un sistema parlamentario puro, sobre la base de la ineficacia del sistema presidencial (a la que una fórmula mixta no conseguiría poner $\mathrm{fin}^{94}$ ) y la consolidación de la democracia ${ }^{95}$. Esta

93 No obstante, considerando la relevancia que en todo proceso de transición democrática reviste el sistema de gobierno, se constata que durante los años setenta y ochenta fue muy escasa la teoría sobre el presidencialismo fuera de los Estados Unidos. Como honrosa excepción ha de mencionarse a LINZ, quien en un artículo de un seminario que desde 1985 circulaba sin publicar, argumentaba que los sistemas presidenciales poseían una debilidad inherente que les hacía menos favorables para sustentar la democracia que los sistemas parlamentarios. Así lo pone de manifiesto Scott Mainwaring, «Presidencialismo, Multipartidismo y Democracia...", op. cit., pp. 115-116.

94 Un estudio sobre la capacidad operativa, entendida como aptitud para la ejecución de las actividades que le son asignadas, del Poder Ejecutivo en América Latina de la mano de Waldino Suárez, "El Poder Ejecutivo en América Latina: su capacidad operativa bajo regímenes presidencialistas de Gobierno", op. cit., pp. 109-144. Concretamente, va a exponer cómo cinco tipos de limitaciones propias del sistema presidencialista de tipo constitucional adoptado en América Latina (la duración rígida del período presidencial, la importancia otorgada a los outsiders durante la campaña electoral, el consecuente desorden que lo último introduce en el sistema de partidos, el conflicto crónico entre Poder Ejecutivo y Poder Legislativo y los límites constitucionales estrictos impuestos sobre el Poder Ejecutivo) han constituido un impacto importante en el desarrollo de formas de liderazgo y sucesión y afectan a la capacidad operativa del Poder Ejecutivo en América Latina. Así «[...] es probable [...] que el gobierno presidencialista sea ineficaz, conduzca al autoritarismo y sea más inestable que cualquier otra forma de gobierno». Sobre esta premisa, este autor propone el abandono de algunas formas presidencialistas y la consideración de la alternativa semipresidencial.

95 Sobre el proceso de transición y consolidación de la democracia, véase el artículo de Carmen Ninou Guinot, "Transición y Consolidación Democrática en América Latina», Revista de Estudios Políticos, N 82, Octubre-Diciembre 1993; Juan 
postura argumenta que las características del gobierno presidencial (como la dualidad de poderes con legitimidades democráticas independientes, el mandato fijo e inalterable y la naturaleza unipersonal del cargo) acarrean una serie de consecuencias negativas: tensiones entre Ejecutivo y Legislativo, tendencia hacia la personalización de la política y otorgamiento de ventajas hacia personas con escasa experiencia administrativa (outsiders), escaso interés presidencial por la conformación de alianzas con otros partidos políticos e imposibilidad de remover a un Ejecutivo impopular o de reelegir al que se ha mostrado eficaz, todo lo cual conduce a la inestabilidad e incluso al autoritarismo ${ }^{96}$.

Por su parte, en Argentina se defiende desde el foro académico la evolución hacia sistemas mixtos ${ }^{97}$. Los que se inclinan por esta opción,

Carlos Torre, "América Latina. El gobierno de la democracia en tiempos difíciles», Revista de Estudios Políticos, N 74, 1991, pp. 145-161 y Nikolaus Werz, "Democracy and forms of government in South America), Law and State, vol. 39, 1989, pp. 99 a 131. La cuestión más específica del juego de la democracia y la política es abordada por Menno Vellinga (coord.), Democracia y política en América Latina, México, Siglo XXI Editores, 1993. Desde el otro extremo, como estudios sobre el autoritarismo en esta región pueden mencionarse: Manuel Barquin Álvarez, "Las formas de gobierno y el desarrollo latinoamericano. (Un reto a la teoría del Estado contemporáneo)", Boletín Mexicano de Derecho Comparado, No 55, Enero-Abril 1986, pp. 37-64, donde se recogen las críticas del autor hacia O'Donnell al caracterizar al Estado autoritario latinoamericano como «autoritarismo burocrático" y Alberto van Klaveren, "Enfoques alternativos para el estudio del autoritarismo en América Latina», Revista de Estudios Políricos, No 51, Mayo-Junio 1986, pp. 23-52; en este trabajo el autor procede a analizar cuatro escuelas interpretativas en el estudio del autoritarismo en Latinoamérica.

96 El pionero de esta postura fue Linz con su manuscrito "Democracy, Presidential or Parlamentary: Does make a difference?", leido en el seminario de investigación del Programa de Estudios Latinoamericanos de la Georgetown University, en 1989. Otros exponentes de esta postura son: Jean Blondel y Waldino Suárez, "Las limitaciones institucionales del sistema presidencialista", Criterio, $N^{\circ} 1853-1854,1981$, Buenos Aires; Arend Liphart, "Presidenzialismo e Democrazia Maggioritaria", op. cit., pp. 367 384; Scott Mainwaring, "Presidetialism in Latin America: a review essay", Latin American Research Review, No 25, 1991, pp. 157-179.

97 Como ejemplos concretos podemos citar: Romeo Pérez, “El Parlamentarismo. La reforma necesaria en Uruguay»; Mario Fernández Baeza, "Sistema parlamentario en Chile. Entre la razón y la tradición» en Reforma Política y Consolidación Democrática. Europa y América Latina, Nueva Visión, Caracas, 1988 y Juan Vicente Sola, Las dos caras del Estado. Presidente y Primer Ministro en una Argentina Moderna, Sudamérica-Planeta, Buenos Aires, 1988 , citados en Mario D. Serrafero, "Presiden- 
no consideran viable la instauración del modelo parlamentario en el ámbito iberoamericano por razones de cultura política y por la conveniencia de conservar algunos aspectos del presidencialismo, a fin de lograr una definitiva consolidación de la democracia. El sistema semipresidencial muestra una gran facilidad para adaptarse a las variadas circunstancias institucionales que pueden plantearse en un país, mientras que el presidencialismo ha demostrado ser sumamente rígido y no ha sabido arbitrar caminos de salida frente al desgaste sufrido por la figura del jefe del Estado. El carácter colegiado del Poder Ejecutivo brinda una estructura dentro de la cual la figura del presidente encuentra grandes posibilidades de ser preservada frente a los embates del ejercicio del poder ${ }^{98}$.

Semejante propuesta mixta apunta el chileno Nogueira Alcalá, quien rechaza la alternativa del parlamentarismo y propone una forma de gobierno semipresidencial caracterizada por un dualismo en el Ejecutivo en cuyo seno pretende una cierta preeminencia en favor del Presidente de la República, moderador del juego político. El gobierno, con el Primer ministro al frente, sería responsable ante el Parlamento, existiendo como mecanismos de relación la disolución discrecional y la moción de censura constructiva ${ }^{99}$. Para Virgala Foruria, la propuesta de un dualismo en el Ejecutivo constituye un elemento desestabilizador, tal y como lo demuestra la experiencia francesa; además, la adopción de la moción de censura constructiva no ha tenido resultados apreciables ni en España ni en Alemania, en la medida en que la estabilidad gubernamental en ambos países ha venido determinada por sus sistemas de partidos. Más funcional y eficaz le parecen las propuestas de los racionalistas norteamericanos dirigidas a la reforma de la forma de gobierno en el sentido semiparlamentario (el autor opta por este térmi-

cialismo y Reforma Política en América Latina», op. cit., pp. 200-201. En las pp. $222-$ 223 y 227-228 del mismo artículo, podemos encontrar una concreta referencia a la cuestión de la eficacia y el «bloqueo" interpoderes como deficiencias de las que adolece el régimen presidencialista a la hora de enfrentarse a la resolución de problemas y demandas ciudadanas. Por último, hemos de mencionar Daniel Alberto Sabsay, «El Semipresidencialismo: una visión comparada", en Nino y otros, El Presidencialismo puesto a prueba, op. cit., pp. 197 a 214 y Juan Vicente Sola, Las dos caras del Estado: Presidente y Primer Ministro en una Argentina moderna, op. cit.

98 Daniel Alberto Sabsay, «El Semipresidencialismo...», op. cit., pp. 211 a 214.

99 Humberto Nogueira Alcalá, "I Regimi Presidenziali...", op. cit., p. 524. 
no y decide reservar el de semipresidencialismo para designar a las formas de gobierno similares a la establecida en la Constitución francesa de 1958). Dicha opción consistiría en una combinación, en el marco de la experiencia norteamericana, de algunos aspectos parlamentarios con una estructura esencialmente presidencialista. En otras palabras, una forma de gobierno que, conservando algunos de los grandes aciertos de su experiencia constitucional (legitimación popular del Presidente, poder presidencial de dirección de la política exterior, importantes funciones de control encomendadas al Congreso) no incluya los evidentes defectos que también ha proporcionado la misma (existencia del denominado gobierno dividido, fruto de su sistema electoral y de la debilidad de los partidos políticos, imposibilidad de dar solución a los bloqueos institucionales). Lo fundamental de su propuesta es la introducción de mecanismos de resolución de conflictos institucionales propios de la forma de gobierno parlamentaria (disolución, moción de censura), pero que conduzcan necesariamente a la toma de una decisión por los ciudadanos favorable a una de las dos posiciones institucionales enfrentadas mediante la realización de elecciones simultáneas a la presidencia y al Congreso ${ }^{100}$.

Tampoco faltan los sectores que defienden el mantenimiento del sistema presidencial con base en los argumentos de la tradición política, experiencia histórica y las concretas realidades políticas. Así, en México nadie piensa que la democracia deba ser parlamentaria, sino que todas las partes implicadas en el cambio político dan por sentado la continuidad del régimen presidencial (y del federalismo). El debate se produce, por tanto, en torno a las claves de la continuidad del sistema presidencial ${ }^{101}$.

100 Eduardo Vírgala Foruria, “La forma de gobierno semiparlamentaria...», op. cit., pp. 121-134.

101 Sírvanos de ejemplo la postura de Lujambio, quien participa en este debate de continuidad abordando una concreta cuestión: la manera en que la continuidad de la presencia de -y la interacción entre- los sistemas presidencial (por naturaleza mayoritario y excluyente) y federal (por naturaleza consensual e inclusivo) están influyendo en las características y el ritmo de la transición mexicana a la democracia. Lujambio, Alonso, "Régimen presidencial, democracia mayoritaria y los dilemas de la transición a la democracia en México", en Alicia Hernández Chavez (coord.), Presidencialismo y sistema político. México y los Estados Unidos, El Colegio de México, Fondo de Cultura Económica, México, 1994 ( $1^{\text {a }}$ edición), pp. 75-111. Otro 
Por otra parte, Nohlen aborda este debate desde la perspectiva metodológica ${ }^{102}$.

El debate sobre el presidencialismo, ya lo apuntábamos, también se ha planteado en el ámbito de las propuestas gubernamentales de reforma política gubernamental, donde la cuestión de la forma de gobierno adecuada para lograr la consolidación democrática ha acaparado una atención preeminente. En Venezuela, el proyecto de reforma integral del Estado de 1988 pretendía descongestionar la tarea del presidente y mejorar los medios técnicos con los que cuenta por medio de la reestructuración de la Oficina del Presidente de la República. En Argentina, el proyecto elaborado por el Consejo para la Consolidación de la Democracia (1987) argumentaba que el elemento central para la consolidación democrática pasa por la sustitución del sistema presidencialista por otro de tipo «mixto" (semipresidencial o semiparlamentario), que aunque mantendría el cargo presidencial, atenuaría el efecto de sus prerrogativas e introduciría elementos propios del parlamentarismo. Como es por todos conocido, en Brasil ante la inexistencia de acuerdo entre los constituyentes, si bien se adopta el sistema presidencial, se posterga la decisión definitiva de la cuestión hasta la celebración de un plebiscito a celebrarse en 1993, que decidiría sobre las formas definitivas del régimen político, optando entre la monarquía y la República y

autorizado autor que se decanta a favor de la continuidad del sistema presidencialista es Jorge Carpizo, quien argumenta que éste es el que mejor responde a la situación mexicana. Jorge Carpizo, "Algunas reflexiones sobre los cambios en el presidencialismo mexicano» (1978-1990), Boletín Mexicano de Derecho Comparado, N 70, 1991, pp. 95-96.

102 En primer lugar advierte sobre el «espejismo estadístico" que asocia estabilidad democrática, proceso socio-económico y formas parlamentarias. Esa posición olvida los derrumbes de las democracias parlamentarias y semiparlamentarias de la Europa de entreguerras y la estabilidad que durante décadas gozó el presidencialismo en Iberoamérica. También señala que la postura contraria, la que afirma que si las democracias latinoamericanas hubieran tenido un sistema parlamentario no hubieran sufridos quiebres, tampoco convence. En definitiva, para Nohlen el debate se circunscribe a tipos ideales y ello "conduce a una grave deformación teórica y práctica". Las comparaciones deben efectuarse entre las variantes de los sistemas básicos. Dieter Nohlen, "Presidencialismo v. Parlamentarismo", Revista de Estudios Políticos, N 74, 1991, pp. 43-54. 
entre la forma de gobierno presidencial y la parlamentaria (Disposiciones Transitorias Artículo 20$)^{103}$.

Así pues, es constatable la tendencia de las nuevas constituciones presidencialistas iberoamericanas de modificar el sistema clásico con matices parlamentarios y principios más democráticos (ampliación de la legitimación para ejercer la iniciativa popular, mayor participación popular en la toma de decisiones...) que pretenden mitigar el poder presidencial y suavizar y coordinar las relaciones entre Poder Ejecutivo y Poder Legislativo ${ }^{104}$.

Se adopte la forma que se adopte, pensamos que la transformación del presidencialismo iberoamericano ha de pasar necesariamente por el recorte del poder del cargo de Presidente de la República y el otorgamiento de un mayor peso específico al Parlamento, así como por la construcción de un sistema de partidos más eficaz.

103 Más detalladamente, Mario D. Serrafero, «Presidencialismo y Reforma Política en América Latina", op. cit., pp. 198-200.

$104 \mathrm{El} \mathrm{ejemplo} \mathrm{más} \mathrm{ilustrativo} \mathrm{de} \mathrm{la} \mathrm{plasmación} \mathrm{de} \mathrm{estos} \mathrm{principios} \mathrm{se} \mathrm{encuentra}$ en el seno de la Constitución de Guatemala: prevé una única Cámara, una amplia iniciativa legislativa, mecanismos de participación y consulta popular, veto total y prohibe las habilitaciones legislativas. 